OPEN ACCESS

Edited by:

Alessio Fasano,

Massachusetts General Hospital and Harvard Medical School, United States

Reviewed by:

Yogesh Singh,

Tübingen University Hospital,

Germany

Michael Kogut,

United States Department of

Agriculture, United States

*Correspondence:

Ruggiero Francavilla rfrancavilla@gmail.com

Specialty section:

This article was submitted to

Mucosal Immunity,

a section of the journal

Frontiers in Immunology

Received: 30 June 2020

Accepted: 14 January 2021

Published: 26 February 2021

Citation:

Cristofori F, Dargenio VN, Dargenio C,

Miniello VL, Barone $M$ and

Francavilla $R$ (2021) Anti-Inflammatory

and Immunomodulatory Effects of

Probiotics in Gut Inflammation:

A Door to the Body.

Front. Immunol. 12:578386.

doi: 10.3389/fimmu.2021.578386

\section{Anti-Inflammatory and Immunomodulatory Effects of Probiotics in Gut Inflammation: A Door to the Body}

\author{
Fernanda Cristofori ${ }^{1}$, Vanessa Nadia Dargenio ${ }^{1}$, Costantino Dargenio ${ }^{1}$, \\ Vito Leonardo Miniello ${ }^{1}$, Michele Barone ${ }^{2}$ and Ruggiero Francavilla ${ }^{1 *}$ \\ 1 Department of Biomedical Science and Human Oncology, University of Bari Aldo Moro, Bari, Italy, ${ }^{2}$ Gastroenterology Unit, \\ Department of Emergency and Organ Transplantation, University of Bari Aldo Moro, Bari, Italy
}

Hosting millions of microorganisms, the digestive tract is the primary and most important part of bacterial colonization. On one side, in cases of opportunistic invasion, the abundant bacterial population inside intestinal tissues may face potential health problems such as inflammation and infections. Therefore, the immune system has evolved to sustain the hostmicrobiota symbiotic relationship. On the other hand, to maintain host immune homeostasis, the intestinal microflora often exerts an immunoregulatory function that cannot be ignored. A field of great interest is the association of either microbiota or probiotics with the immune system concerning clinical uses. This microbial community regulates some of the host's metabolic and physiological functions and drives early-life immune system maturation, contributing to their homeostasis throughout life. Changes in gut microbiota can occur through modification in function, composition (dysbiosis), or microbiota-host interplays. Studies on animals and humans show that probiotics can have a pivotal effect on the modulation of immune and inflammatory mechanisms; however, the precise mechanisms have not yet been well defined. Diet, age, BMl (body mass index), medications, and stress may confound the benefits of probiotic intake. In addition to host gut functions (permeability and physiology), all these agents have profound implications for the gut microbiome composition. The use of probiotics could improve the gut microbial population, increase mucus-secretion, and prevent the destruction of tight junction proteins by decreasing the number of lipopolysaccharides (LPSS). When LPS binds endothelial cells to toll-like receptors (TLR 2, 4), dendritic cells and macrophage cells are activated, and inflammatory markers are increased. Furthermore, a decrease in gut dysbiosis and intestinal leakage after probiotic therapy may minimize the development of inflammatory biomarkers and blunt unnecessary activation of the immune system. In turn, probiotics improve the differentiation of T-cells against Th2 and development of Th2 cytokines such as IL-4 and IL-10. The present narrative review explores the interactions between gut microflora/probiotics and the immune system starting from the general perspective of a biological plausibility to get to the in vitro and in vivo demonstrations of a probiotic-based approach up to the possible uses for novel therapeutic strategies.

Keywords: probiotics, microbiota, inflammation, celiac disease, inflammatory bowel disease, irritable bowel syndrome, obesity, autism spectrum disorders 


\section{INTRODUCTION}

On 23 February 2004, Time Magazine dedicated the cover to chronic inflammation with a provocative title: The Secret Killer. The hypothesis is that, if we think of inflammation from an evolutionary point of view, we are now the victims of our own success. We developed as a species because of our capacity to eliminate dangerous microbial species, but the survival tactics used by our immune system, that was necessary at a time when there were no antibiotics or drainage systems, turned against us. An excess of inflammation and the inability to stop this system can do more harm than good. Chronic inflammation occurs at varying degrees with advanced age in all mammals, regardless of infection and progresses gradually. This is, in part, the cause of many inflammatory chronic diseases (ICDs) and poses a significant threat to human health and longevity. Chronic inflammation follows the failure of the immune system to shut down its reaction to a real or alleged attack. The inability of the body to eliminate an inflammation-inducing agent is the cause of a pro-inflammatory state that can spread all over the body. The health status in our industrialized population is endangered by a plethora of ICD characterized by a widespread and latent lowgrade inflammation. These include allergy, certain autoimmune diseases such as Celiac Disease (CeD), Inflammatory Bowel Disease (IBD), Irritable Bowel Syndrome (IBS), obesity and autism spectrum disorders (ASDs), which often tend to share similar environmental risk factors (1) and genetic risk alleles (2).

\section{MICROBIAL ECOLOGY, HUMAN EVOLUTION, IMMUNE SYSTEM AND INFLAMMATION}

People living in today's urban environments have access to calorie-dense food, minimal physical activity, and high energy balance; moreover, hygiene regimens have decreased, by large, the extent and severity of microbial exposition $(3,4)$. Certain

\footnotetext{
Abbreviations: 5-FU, 5-Fluorouracil; 5-ASA, 5-Aminosalicylic acid; ASDs, Autism Spectrum Disorders; EAE, Autoimmune Encephalomyelitis; B., Bacillus $B B$., Bifidobacterium BMI, Body Mass Index; BMDCs, Bone Marrow-Derived Dendritic Cells; CS, Cesarean Section; CeD, Celiac Disease CFS, Cells Free Supernatant; C., Clostridium; CFU, Colony Forming Unit; CD, Crohn's disease; COX-2, Cyclooxygenase 2; DCs, Dendritic Cells; EcN, Escherichia coli strain Nissle 1917; E., Escherichia; GFD, Gluten-Free Diet; IgA, Immunoglobulin A; IPA, Indole 3-Propionic Acid; IBD, Inflammatory Bowel Disease; ICD, Inflammatory Chronic Disease; IFN, Interferon; IL, Interleukin; IBS, Irritable Bowel Syndrome; K., Kluyveromyces; LAB, Lactic Acid Bacteria; L., Lactobacillus; LPS, Lipopolysaccharides; MAPKs, Mitogen-Activated Protein Kinases; MCP-1, Monocyte chemotactic protein-1; NK, Natural Killer; NEC, Necrotizing Enterocolitis; NOS, Nitric Oxide Synthase; NF- $\kappa$, Nuclear Factor kappa-lightchain-enhancer of activated B cells Pathway; PD, Parkinson's Disease; PRRs, Pattern Recognition Receptors; PBMCs, Peripheral Blood Mononuclear Cells; PSA, Polysaccharide A; PB, Postbiotic; RCT, Randomized Clinical Trial; Breg, Regulatory B Cells; Treg, Regulatory T Cells; S., Saccharomyces; SFAs, Saturated Fatty Acids; SCFA, Short-Chain Fatty Acid; sVCAM-1, Soluble Vascular Cell Adhesion Molecule 1; Th cells, T helper cells; TLRs, Tool Like Receptors; TNBS, Trinitrobenzoate; TMAO, Trimethylamine N-oxide; TGF, Tumor growth factor; TNF, Tumor Necrosis Factor; UC, Ulcerative colitis; VCAM-1, Vascular Cell Adhesion Molecule 1; WDS, Western-Type Diets.
}

bacteria, called "old-friends" such as lactobacilli, have been a species of microorganisms that have become part of the human ecosystem for centuries and are usually regarded as harmless to their hosts and in the last decades we are losing our "old-friends". The immune system evolves and operates in an ecosystem that is an integral part of its natural environment $(5,6)$ and a dramatic shift of this environment, such as that we are experiencing today, may alter a millennial balance of co-evolution causing a mismatch responsible of an increase of a disease state.

We have evolved in condition with suboptimal nutritional status and significant levels of microbial contact, while today, we are an over-nourished, under-infected industrial population (68). Given the crucial significance of new environments in shaping the development and functioning of the human immune system, the make-up of the intestinal microbiota plays a significant role in its training. Emerging literature indicates significant variability in human immune growth and function, and the process of microbial colonization starting at birth and consolidated in the first thousand days is an essential determinant of individual immune responses.

The hygiene hypothesis supports a negative correlation between infancy microbial exposures and inflammation in adults: low rates of microbial contact soon in life, appear to contribute to the dysregulation of immune function and regulatory processes that raise the risk of ICD later in life (911). Frequent yet temporary interactions with bacteria can be significant in this process, such as local environment can affect the make-up of resident bacterial populations in the human intestine that have long-lasting effects on immunity (12). Mechanisms behind these adaptations are not simple and include the regulation of $\mathrm{T}$ cells and the balance between proand anti-inflammatory cytokine composition $(10,13)$.

Conceptually, microbial exposures play a significant role in developing successful regulatory networks in vulnerable periods of childhood immune shaping. Less hygienic conditions increase the incidence and abundance of bacterial sources, resulting in an increased ability to control inflammation. Differently, extra hygienic conditions reduce the extent and severity of bacterial contact in children, restrict incentives for turning on and off of inflammatory processes during crucial phases of immune shaping. The effect is a pro-inflammatory phenotype. Later in life, when inflammatory processes are activated, there is an inadequate anti-inflammatory regulation resulting in a persistent chronic state of activation.

Early life dietary and bacterial exposures, facilitate the growth of more effective immune defenses and its ability to hone the inflammatory regulation mechanisms encouraging the emergence of an effective adaptive immune system. These findings underscore the function of infant environments in influencing several facets of an immune-phenotype and point to the significance of bacterial exposures.

\section{IMMUNE SYSTEM AND GUT BACTERIA}

We lived in a bacteria world and developed a symbiotic state with our bacteria that may raise safety issues. The large bacterial population in the lower intestine are in close contact with human 
structures, and to separate the inside from the outside, there is just a single cell layer on a vast surface. This close contact with bacteria, if not controlled, can give rise to threatening health complications. Therefore, the immune system has put in place mechanisms to maintain a symbiotic bond between its guests. The need to maintain a homeostatic relationship with the microbiota has been a driving factor force in the evolution of the human immune system and to keep the gut microbiota for its essential role in host metabolism and functions (14).

This alliance was reached by a fine-tuned contact modulation between gut bacteria and intestinal epithelial cells and by limiting the possible entrance of bacteria trough the mucosal layer. In case of an occasional breach in the gut barrier, microorganisms can infiltrate the intestinal epithelial cell and evoke an immune response guided by mucosal dendritic cells (DCs) able to induce a defensive secretory Immunoglobulin A (IgA) response (15).

Studies in germ-free and colonized mice showed how significant is the impact of the gut bacteria on the shaping of the immune system. It has recently become clear that human commensal organisms have an impact on the structure of gut $\mathrm{T}$ lymphocyte function. The healthy balance in the intestinal district is preserved by the circuitry of monitoring mechanisms between potentially pro-inflammatory cell [ $\mathrm{T}$ helper (Th) cells secreting interferon (IFN)- $\gamma$, Th17 cells that secrete interleukin (IL)-17, and IL-22], and anti-inflammatory Foxp3+ receptor Tcells [Regulatory T (Treg) Cells)]. Many bacteria can stimulate the anti-inflammatory fork of the adaptive immune system by controlling Treg maturation or by driving IL-10 production. In instance, Atarashi $\mathrm{K}$ et al. have demonstrated that a mix of 46 strains of Clostridia clusters IV and XIVa, colonizing gnotobiotic mice can induce a local and systemic Treg cell response (16). Besides, Bacteroides fragilis polysaccharide A (PSA) elicit an IL10 response in gut $\mathrm{T}$ cells that prevent the spread of TH17 cells responsible for derangement of the intestinal wall (17). On the other hand, mutant Bacteroides fragilis without PSA has an opposite inflammatory behavior and does not induce IL-10. It has become clear that the impact of gut bacteria and T cell cooperation goes beyond the intestinal site and can have an effect on systemic in areas far from the gut (18). The type of microbial establishment is the driving force in numerous mouse models of autoimmune conditions such as arthritis and experimental autoimmune encephalomyelitis (EAE) in which the disease state of activation is dependent on gut microbiota composition. Lee YK and Wu HJ et al. in a model of Th17 cell-dependent arthritis and EAE, have demonstrated that colonization with segmented filamentous bacteria is able to set off the disorder (1921 ) indicating that the gut bacteria have a systemic immune effect that extends far from the mucosal site.

Under normal conditions, careful regulation restricts excessive inflammation and maintains an immune balance (22-25) that if lost increases the susceptibility for ICDs (2628). The disruption of nutrition-microbiome-host-metabolism interrelationships is commonly functionally described as "dysbiosis" that is a is a recurring element of various ICDs $(23,25)$.

\section{ESTABLISHMENT OF THE HUMAN GUT MICROBIOTA}

The human gut microbiota develops in composition and function in the first years of life (29) reaching a firm microbial population by the second year and an adult-like profile by the time of 4 years (30). This steady-state is driven by a complex interplay between climate, food, microbes, and host factors (31, 32). Babies born by cesarean section (CS) develop a microbiota that resembles that of the skin of the mother. Conversely, the microbiota of a vaginally delivered baby is close to its mother's vagina and characterized by lactobacilli and bifidobacteria (33). The capacity of cross-talking between microbes and the immune system is mandatory to allow bacterial priming and maturation of the immune system, considering that $70 \%$ of immune cells are resident in the gut. In addition to CS (34-36) antibiotics (31), breastfeeding $(34,36)$, and solid food introduction (29), guide the development of gut microbiota. Infants born with CS are more likely to have respiratory disease (37) and are at increased risk for atopy/asthma (38), obesity (39), and type-1 diabetes (40).

\section{WESTERN LIFESTYLE, DIET AND CHRONIC INFLAMMATION}

Western lifestyle can trigger an aberrant innate immune activation and disease pathogenesis; recent data suggest that the western lifestyle can set off a systemic inflammatory arrangement leading to health issues typical of industrialized countries.

Among western lifestyle, the main contribution is the adherence to western-type diets (WDs) progressively expanded to low-income nations, with a concurrent increase in ICDs in areas of the planet where these diseases were rare $(41,42)$. The habitual consumption of WDs can impact on host metabolism and fitness by favoring weight increase, alteration of lipid profile, energy metabolism, and immune activation and promoting several chronic metabolic disorders (obesity, type-2 diabetes mellitus, cardiovascular diseases, and neurodegenerative and autoimmune diseases).

WDs are high in simple sugars, white flour, salt, processed meats, animal fats and food additives, and poor of fiber, minerals, vitamins, or antioxidants $(43,44)$. The immediate consequence is a rapid weight gain (45). A quick look to the ingredients of WDs allows identifying the components able to elicit an inflammatory response: cholesterol, refined sugars, dairy products, and saturated fatty acids (SFAs) (46). The composition of gut bacteria under the pressure of WD undergoes a profound modification that results in derangement of the eubiotic state. This new microbial balance is responsible for the secretion of microbial metabolites that can reach the systemic circulation, can cause derangement of intestinal permeability that can potentially induce endotoxemia and systemic inflammatory (47). Tanoue T. et al. have demonstrated that mice fed with WD develop a profound dysbiosis leading to immune dysfunction resulting in: a) decrease in mucous secretion, b) loss of secretive IgA function, 
c) inhibition of Treg cells producing IL-10, d) impaired barrier integrity, e) loss of immune homeostasis, that is the premise for the future onset of ICD (autoimmune and allergy) (48).

Red meat, eggs, and milk-based products coupled with a low intake of fruits and veggies are connected with changes in the intestinal microbial composition, gut inflammation (49). Dietary L-carnitine is metabolized into a metabolic product known as trimethylamine $\mathrm{N}$-oxide (TMAO). The production of this metabolite is dependent on a microbial fermentation occurring in anaerobiosis (49). TMAO is able to activate macrophage and platelet inflammatory response causing endothelial dysfunction, vascular inflammation, and ultimately increasing the risk of cardiovascular disease (50). Caesar et al. demonstrated that WD, particularly saturated fats, influences gut microbiota and causes the inflammation of adipose tissue; conversely, unsaturated fats protect animals from this complication. Interestingly, the authors show that the health-promoting effect is mediated by the microbiota since the transfer of gut microbes from unsaturated to saturated fat-fed mice reduces white adipose tissue inflammation (51).

Is it possible to compensate for the loss of the optimal microbiota with the use of probiotics? The answer is "we still do not know," but emerging data show that in a not too distant future, selected strains of probiotics may be used to direct the immune response towards the path we need.

\section{GUT DYSBIOSIS}

The gut microbiota is a microbial ecosystem that has a dramatic role in human health, and it is particularly challenging to define a healthy microbiota; however, this is of great importance if we aim to prevent/correct the alterations of its composition that can impact on our health. There is no "one normal microbiota" since the degree of variability makes it impossible to define what is normal; however, there are some characteristics that can help us to determine a microbiota as healthy: increased diversity, gene richness, amount of butyrate-producing species and resilience.

Resilience is the ability of an ecosystem to withstand alteration under stress or to promptly and thoroughly bounce back from the interference. Therefore, a healthy microbiota is able to recover and go back to baseline after a perturbation (such as an antibiotic treatment) as a result of its resilience avoiding the institution of a new balance and a shift into dysbiosis, with a negative effect on human health (52). As we live, our gut microbiota encounters several perturbators (unhealthy diet, antibiotics, drugs, alcohol, intensive exercise, and pathogenic bacteria). If it is not able to oppose to these attacks, a permanent change occurs leading to a new balance which might not be healthy: this is what we call dysbiosis.

Gut dysbiosis relates to differences in the composition and activity of the gut microbiota that, through qualitative and quantitative shifts in the gut bacteria itself, changes in its metabolic activities and/or changes in its local distribution, have detrimental effects on host health (53). Certain commensal bacteria inhibit the growth of opportunistic pathogens. For instance, during lactose fermentation, Bifidobacterium decreases intestinal $\mathrm{pH}$, hence preventing colonization by pathogenic Escherichia (E.) coli. The metabolites of commensal bacteria also directly inhibit the pathogens' virulence genes. If antibiotic treatment subsequently disrupts the resident microbial populations, it may cause inflammation. For example, in colitis mouse model induced by dextran sulfate sodium (DSS), antibiotic increases the abundance of E. coli, encouraging the pathogen's systemic circulation, thus inflammasome activation (54).

Analyzing the importance of dysbiosis-driven diseases in humans, the immune system-gut microbiota crosstalk is of supreme significance. By enhancing the mucosal barrier and fostering innate immune system, commensal bacteria avoid pathogen invasion and infection. It is well-known that the gut microbiota activates the growth and development of the immune response and plays a vital role in immune cell maturation, too. Gut microbial diversity and abundance have been recognized as powerful determinants of host wellbeing, and variations in diversity have been correlated with several human disorders. However, several studies have shown that intestinal microbiota, through complex interactions between intestinal microbiota, host metabolism, and immune systems, directly contribute to the pathophysiology of specific diseases (55). The relationship between gut dysbiosis and inflammation of the mucosa is either a cause or a consequence of dysbiosis, or a combination of both, with one study indicating that intestinal microbiota is necessary for the initiation and progression of inflammation of the mucosa in germ-free mice.

The mucosal barrier formed by intestinal epithelial cells serves as a defense measure, isolating bacteria from host immune cells. Altering the epithelial membrane raises the sensitivity to infection and the delivery of microbial metabolites to the host. Gut dysbiosis not only decreases the stability of the mucosal barrier but also disrupts the immune system, inducing oxidative stress and inflammation. Over time, chronic intestinal dysbiosis and bacterial translocation of bacteria can increase the prevalence of a variety of diseases. Below, we illustrate conditions with detailed research and clinical models relating the mucosal immune system and inflammation, the occurrence of disease and severity.

\section{PROBIOTICS AND INFLAMMATION}

Several strains of probiotics have been shown to exert multiple and varied effects on the host and its immune system (56). Their essential role in inflammatory regulation has been well elucidated in several in vitro and ex vivo models and in germfree mice showing the failure of the systemic immune regulatory networks, which triggers a cascade of events leading to an inflammatory response.

Specific bacterial strains can act on the gut luminal environment, intestinal mucosal barrier, and they can regulate the mucosal immune system. Probiotics may affect different cells involved in the innate and acquired immunity, for instance, DCs, monocytes, Natural Killer (NK) cells, macrophages, lymphocytes 
and epithelial cells (see Figure 1). In particular, they may activate the pattern recognition receptors (PRRs) expressed on immune (i.e. $\mathrm{M}$ cells in Peyer's patches) and non-immune cells (i.e. intestinal epithelial cells). Among PRRs, TLRs are the most studied which can activate signaling cascades that lead to cell proliferation and cytokine releasing in order to modulate the immune system (57). Moreover, some specific strains secrete substances that may induce the activation of immune cells. In particular, $M$ cells phagocytize or internalize the probiotic and the antigenic components derived from its metabolites, to form endosomes.

Specific probiotic strains can activate DCs, which transport the antigens to local lymph nodes with the following release of IL-10 and IL-12. Here, DCs induce the differentiation of naive T and $B$ cells into their subpopulations, deploying their arsenal of cytokines. In details, naïe Th cells can differentiate into Treg,

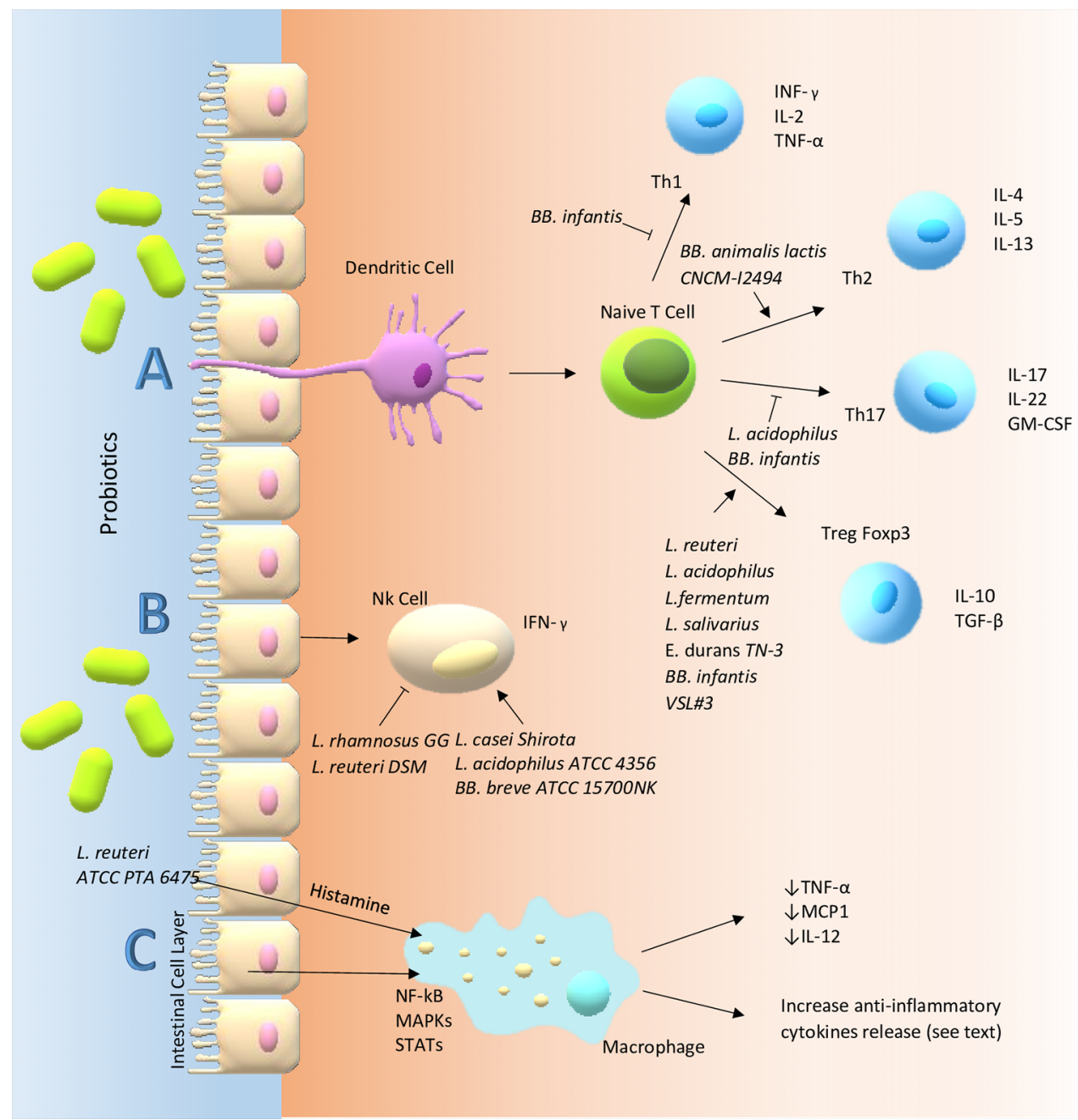

FIGURE 1 | Main probiotic immune-modulatory pathways in the gut. (A) T cells are considered the masters of inflammation in that they can differentiate into different pathways promoting or suppressing inflammatory response. However, their fate requires interaction with other cells: for instance, dendritic cells. Probiotics can influence these communications through membrane receptors e.g. PRRs. In particular, TLR- 6 and TLR-2, a member of PRRs, expressed on sentinel cells such as macrophages and dendritic cells, might be able to decrease the Th17 polarization and skew T-cells toward Treg subpopulation and production of high levels of IL-10 and lower levels of TNF- $\alpha$, reducing the inflammatory state which could be one of the mechanisms involved in the immune modulatory effect of probiotics in inflammatory intestinal diseases. Probiotics seem to redirect the Th2 response, characteristic of atopic patients, towards a Th1 type through increased secretion of IFN- $\gamma$ and a decrease in the IL-4, IL-13, and IgE production with improvement of allergic predisposition and reactions. In the gut, probiotics may activate B cells in the lamina propria that become IgA-producing plasma cells. The IgA, a major functional component of the humoral adaptive immune system specialized in mucosal protection and a first line of defense against gastrointestinal infections, is transported across the epithelial cells and once it is secreted in the gut lumen it can bind to the mucus layer covering them. (B) NK cells are intermediate cells between innate and adapted immunity. They seem to act in different ways through an interplay with intestinal epithelial cells, DCs and T cells. Probiotics can modulate their behavior for instance through the secretion of IFN- $\gamma$. (C) Finally, probiotics exert their functions by altering intracellular pathways of immune cells (e.g. macrophage) through kinases (such as MAP kinase cascade) which in the end activate or suppress transcription factors: STAT, NF- $\mathrm{B}$, Jun-1, Fos. On the other hand, probiotics may act on the same pathway through the metabolism of histamine acting on $\mathrm{H} 2-$ receptors of antigen presenting cells and inducing a reduction of pro-inflammatory cytokines like TNF- $\alpha$, IL-12 and monocyte chemotactic protein- 1. 
Th1, and Th2 immune cells, and B cells may shift in plasma cells, playing an active role in humoral responses, or regulatory $\mathrm{B}$ (Breg) cells, involved in the production of tumor growth factor (TGF)- $\beta$ or IL-10 (58). Furthermore, DCs may stimulate the activation of NK cells through the production of cytokines such as IL-12 and IL-15. Other probiotic microorganisms, in particular several Lactic Acid Bacteria (LAB), may promote IFN- $\gamma$ production by NK cells $v i a$ DCs (59).

Studies have demonstrated that the immune modulation deriving from probiotic bacteria may be due to the release of the anti-inflammatory cytokine in the gut. Nonetheless, the specific molecular interactions between probiotics and host are not well defined (60-62). The most used probiotics in human belong to Lactobacillus (L.), Bacillus (B.), and Bifidobacterium (BB.), but also the genus Saccharomyces (S.) is widely adopted in commercial products. Specific strains of Lactobacillus may modulate the cytokine production by immune cells, and Bifidobacterium induces tolerance acquisition (63). Such different regulatory activities by each probiotic strain are linked to their structure, to the spectrum of mediators released, and to the various pathways that are simultaneously activated $(64,65)$.

The anti-inflammatory effects of probiotics have been studied in vitro, ex vivo and in animal experiments to evaluate cytokine production and immune cell proliferation. In the following sections, we report the recently published evidence of the antiinflammatory effect of several probiotic strains.

\section{In Vitro and Ex Vivo Studies}

The interplay mechanisms between probiotics, intestinal cells, and immune system are summarized in Table $\mathbf{1}$; we report the in vitro and the ex vivo studies published in the last five years. The complex interplay between gut microbiota and immune system, shaped by millions of years of evolution, needs to be deeply explored, in consideration of the rapid technological development, which allows the use of increasingly refined techniques. It is important to underline that these methods are basically used as screening tools. The results of in vitro and animal studies are not definitive requiring further confirmation by double blind placebo controlled clinical trials.

\section{Cytokine and Immune Cell Modulation}

In this section, we present in vivo and in vitro studies conducted to highlight the immunomodulatory functions of probiotics and the mode of action.

One of the most known effects of probiotics is that of promoting a shift from Th2 to Th1 cells, to decrease allergic reactions. Human peripheral blood lymphocytes and peripheral blood mononuclear cells (PBMCs), in the presence of LAB, are

TABLE 1 | In vitro and ex vivo studies of different probiotic strains effects in modulating inflammation.

\begin{tabular}{|c|c|c|c|c|}
\hline Reference & Probiotic strains & Doses/different concentrations of probiotic suspensions & $\begin{array}{l}\text { Studied } \\
\text { model }\end{array}$ & $\begin{array}{l}\text { Effect on cytokine patterns and } \\
\text { inflammatory mediators }\end{array}$ \\
\hline $\begin{array}{l}\text { B. K. Thakur et } \\
\text { al. (66) }\end{array}$ & L. casei Lbs2 & $\begin{array}{l}1 \times 10^{9} \\
\mathrm{CFU} / \mathrm{ml}\end{array}$ & In vitro & $\uparrow \mathrm{IL}-10$ and TGF- $\beta$ \\
\hline $\begin{array}{l}\text { S. Eslami et al. } \\
(67)\end{array}$ & L. crispatus SJ-3C-US & $200 \mu \mathrm{g} / \mathrm{ml}$ & In vitro & $\uparrow I \mathrm{~L}-10$ and TGF- $\beta$ \\
\hline $\begin{array}{l}\text { Y. Haileselassie } \\
\text { et al. (68) }\end{array}$ & L. reuteri 17938 & $5 \%$ CFS & In vitro & $\uparrow$ FOXp3 and IL-10 \\
\hline $\begin{array}{l}\text { M.A Johansson } \\
\text { et al. (69) }\end{array}$ & $\begin{array}{l}\text { L. rhamnosus GG } \\
\text { L. reuteri DSM } 17938\end{array}$ & $2.5 \%$ CFS & In vitro & $\begin{array}{l}\downarrow \mathbb{N} N-\gamma \\
\text { Inhibited T cells and NK cell activation }\end{array}$ \\
\hline $\begin{array}{l}\text { I. M. Smith et al. } \\
\text { (70) }\end{array}$ & $\begin{array}{l}\text { K. marxianus } \\
\text { S. boulardii }\end{array}$ & $1 \times 10^{7} \mathrm{cells} / \mu \mathrm{l}$ & In vitro & $\begin{array}{l}\text { Both: } \uparrow \mathrm{IL}-12, \mathrm{IL}-1 \beta, \mathrm{IL}-6, \mathrm{IL}-10 \\
\text { S. boulardii: } \uparrow \mathrm{INF}-\gamma\end{array}$ \\
\hline C. $\operatorname{Ren}(71)$ & $\begin{array}{l}\text { L. plantarum CCFM634 } \\
\text { L. plantarum CCFM734 } \\
\text { L. fermentum CCFM381 } \\
\text { L. acidophilus CCFM137 } \\
\text { S. thermophilus CCFM218 }\end{array}$ & $\begin{array}{l}\text { Cells to bacteria ratios of } 1: 10 \\
1: 20 \\
1: 40\end{array}$ & In vitro & $\begin{array}{l}\text { Stimulated TLR2/TLR6 heterodimer } \\
\text { receptor }\end{array}$ \\
\hline D. Compare (72) & L. casei DG & $1 \times 15^{7} \mathrm{CFU}$ & Ex vivo & $\begin{array}{l}\downarrow \| \mathrm{IL}-1 \alpha, \mathrm{IL}-6, \mathrm{IL}-8 \\
\text { Increased TLR4 expression }\end{array}$ \\
\hline $\begin{array}{l}\text { S. De Marco et } \\
\text { al. (73) }\end{array}$ & $\begin{array}{l}\text { L. acidophilus ATCC } 4356 \text { L. } \\
\text { casei ATCC } 334\end{array}$ & $\begin{array}{l}1 \times 108 \mathrm{CFU} / \mathrm{ml} \\
\text { Cells treated CFS }(10 \% \mathrm{v} / \mathrm{v})\end{array}$ & In vitro & $\begin{array}{l}\text { Both: } \downarrow \text { TNF- } \alpha \uparrow I L-10 \\
\text { L. casei: } \downarrow \mathbb{I L}-1 \beta\end{array}$ \\
\hline $\begin{array}{l}\text { M. Sichetti et al. } \\
(74)\end{array}$ & $\begin{array}{l}\text { L. rhamnosus } \\
\text { BB. lactis } \\
\text { BB. longum (Serobioma) }\end{array}$ & $\begin{array}{l}\left.2 \times 10^{6} \mathrm{PBMC}: 2 \times 10^{5} \mathrm{CFU}\right),\left(2 \times 10^{6} \mathrm{PBMC}: 2 \times 10^{6} \mathrm{CFU}\right) \\
\left(2 \times 10^{6} \mathrm{PBMC}: 2 \times 10^{7} \mathrm{CFU}\right)\end{array}$ & In vitro & $\begin{array}{l}\uparrow I L-10 \\
\downarrow I L-1 \beta \text { and IL-6 }\end{array}$ \\
\hline $\begin{array}{l}\text { M. Kawano et } \\
\text { al. (18) }\end{array}$ & L. helveticus LH2171 & $10 \mu \mathrm{g} / \mathrm{ml}$ & In vitro & $\begin{array}{l}\downarrow \| \mathrm{L}-6 \text { and } \mathrm{IL}-1 \beta \\
\text { Inhibited NF- } \kappa \mathrm{B} / \mathrm{MAPKs}\end{array}$ \\
\hline S.C. Li et al. (75) & $\begin{array}{l}\text { L. acidophilus and } \\
\text { BB. animalis subsp. lactis }\end{array}$ & $\begin{array}{l}\text { Cells to bacteria ratios } \\
\text { of } 1: 1,1: 10\end{array}$ & In vitro & $\begin{array}{l}\downarrow \| \mathrm{L}-8 \\
\text { Inhibited p-p65 NF- } \mathrm{B} \text {, p-p38 MAPK, } \\
\text { VCAM-1 and COX-2 } \\
\text { Increased TLR2 expression }\end{array}$ \\
\hline $\begin{array}{l}\text { V. Sagheddu et } \\
\text { al. (76) }\end{array}$ & L. reuteri LMG P-2748 & $1 \times 108 \mathrm{CFU} / \mathrm{ml}$ & In vitro & $\uparrow I L-10$ \\
\hline
\end{tabular}


able to increase the IFN- $\gamma$ production by T and NK cells $(77,78)$. These results are in agreement with an in vitro experiment showing that lactobacilli found in fermented food strongly induced pro-IFN- $\gamma$ monokine IL-12 and IL-18 production by human or murine leukocytes $(79,80)$. The ability to shift toward a Th2 response might be used in atopy as in other types of Th2 based inflammatory diseases.

Cytokine IL- 8 is crucial for the recruitment of immune cells during an inflammatory response. Luerce et al., in a model of colitis-recurrence in CACO-2 cells, demonstrated the ability of $L$. lactis NCDO 2118 to reduce the IL- 8 secretion induced by IL- $1 \beta$ (81). In reality, also BB. animalis subsp. lactis and L. acidophilus may decrease IL- 8 production and the expressions of proinflammatory mediators and increase TLR2 expression in vitro model. This anti-inflammatory action is attained through the modulation of TLR2-mediated Nuclear Factor kappa-lightchain-enhancer of activated $B$ cells $(N F-\kappa B)$ and mitogenactivated protein kinase (MAPK) signaling pathways in inflammatory intestinal epithelial cells (75). Furthermore, Ren et al. showed that several strains such as L. plantarum CCFM634, L. plantarum CCFM734, L. acidophilus CCFM137, Streptococcus thermophilus CCFM218 and L. fermentum CCFM381 enhanced TLR2/TLR6 heterodimer receptor in a strain-specific way; this activity is the initiator of an intracellular signaling network with immune-modulating effects (71). In an ex vivo study based on lipopolysaccharide (LPS) stimulation in colonic mucosa from post-infectious IBD, L. casei DG and one of its postbiotics suppress pro-inflammatory IL- 8 , IL- $1 \alpha$, IL- 6 and TLR-4 expression levels parallel to an increase of IL-10 (72). The use of probiotics has also been studied in necrotizing enterocolitis (NEC) that is one of the leading causes of death in premature newborns. In particular, L. rhamnosus HN001 was studied ex vivo on human intestinal cells from ileus of NEC infants; the authors have shown that this probiotic (both alive or UV-killed) interacts with TLR-9 and suppresses NF- $\kappa$ B inflammatory pathway via TLR-4 inhibition (82).

Among the other immunological players, Treg cells are the masters of immune modulation and tolerance. $L$. reuteri and $L$. casei exert an anti-inflammatory action, upregulating Treg cell activation and IL-10 levels (probably by DC-SIGN receptor on bone marrow-derived dendritic cells (BMDCs). The overall effect is a significant downregulation of pro-inflammatory cascade with inhibition of bystander $\mathrm{T}$ cell proliferation. These strains have been used in in vivo studies in inflammatory diseases, including Crohn's disease (CD) and atopic dermatitis (64). This activity on Treg cells has also been demonstrated for a mix of probiotics $(B B$. Bifidium, L. casei, L. reuteri, L. acidophilus, and Streptococcus thermophiles) able to downregulate $\mathrm{B}$ and $\mathrm{T}$ cell responses with a net production of inhibitory cytokines (83).

Mouse BMDC co-cultured with VSL\#3 (a probiotic combination of four Lactobacillus strains, three Bifidobacterium species, and one Streptococcus strain) produced high concentrations in IL-12p70, IL-23, and IL-10 (84). A multistrain mixture of $L$. rhamnosus, $B B$. lactis and $B B$. longum induced an increase of the level of an IL-10 and a reduction of pro-inflammatory IL-1 and IL- 6 by 70 and $80 \%$ respectively in the human macrophage cell line derived from acute monocytic leukemia patients and macrophages derived from ex vivo human PBMC (74). Thakur et al. demonstrated that in BMDCs grown with both live and heat-killed Lactobacilli (L. casei Lbs2), TLR-2 receptors were triggered on DCs which led to the differentiation of naive Th cells toward Treg cells and production of IL-10 and TGF- $\beta$ (66). Similar results were obtained when human PBMCs were cultured in the presence of L. crispatus SJ-3C-US (which is found in vaginal microbiota from healthy females and seems to be protective against vaginitis and Pelvic Inflammatory Disease) $(67,85)$.

Attention has also been focused on the primers of immunomodulation, i.e. innate immunity.

L. reuteri ATCC PTA 6475 can suppress Tumor Necrosis Factor (TNF) $\alpha$ production induced by LPS through the inhibition of MAPK regulated c-Jun and activator protein-1 pathway (86). A probiotic mixture engagement with regulatory CD11+ DC enhances Treg cells rising the levels of TGF- $\beta$, IL-10, cyclooxygenase-2 (COX-2) and suppress the production of proinflammatory IL-17, IFN- $\gamma$, and TNF- $\alpha$ (83). L. reuteri LMG P27481 is a new strain discovered and studied by Sagheddu et al. This strain is able to induce a significant secretion of IL-10 when exposed to human immature DCs. If compared to other $L$. reuteri strains, it shows higher anti-inflammatory effect. In in vitro co-cultures, L. reuteri LMG P-27481 was able to control the growth of Escherichia (E.) coli, Salmonella and Rotavirus; however, only this strain was able to hinder the growth of Clostridium (C.) difficile. Another excellent property correlated to the genetic background of this probiotic is the ability to metabolize lactose which can be of great importance in case of diarrhea (76). Griet et al., in an in vitro assay on murine macrophages (model of acute lung injury) stimulated with LPS, demonstrated that $L$. reuteri CRL1098 decreased the production of a) pro-inflammatory mediator such as COX-2, b) nitric oxide synthase (NOS) and c) pro-inflammatory cytokines (TNF- $\alpha$ and IL-6) (87). Moreover, soluble factors produced by L. reuteri CRL1098 were also to inhibit TNF- $\alpha$ production by human PBMC (88)

Specific probiotics strains can negatively or positively stimulate NK cells: L. rhamnosus GG and L. reuteri DSM 17938 inhibit the activation of T cells and NK cells and the release of IFN- $\gamma$ from Staphylococcus-aureus-cultured PBMCs (69). On the contrary, heat-killed L. casei Shirota, L. acidophilus ATCC 4356, and BB. breve ATCC $15700 \mathrm{NK}$ increase NK cell activity and enhance their activation (62). The different interplay between probiotic, DCs and NK cells clearly reveals how each strain can differently modulate the immune system and the inflammatory responses; the NK/DC balance is a complex and probiotics may be used to exert beneficial effects (57).

Probiotics were also chosen among other microbiota components such as yeasts. It has been recently demonstrated that Kluyveromyces (K.) marxianus and S. boulardii stimulate DC production of IL-12, IL- $1 \beta$, IL-6, and IL-10. Moreover, $\beta$ glucan, a polysaccharide derived from their cell wall, could positively interact with DC-receptor Dectin-1 leading to the release of IL-1 $\beta$, IL- 6 , and IL-10, but not IL-12. When naïve 
T cells were cultured with DC in the presence of these probiotics, each strain has its own effect: K. marxianus promotes Treg cells and secretion of IL-10, while $S$. boulardii induces a Th1 type response with the production of IFN- $\gamma(70)$. Thomas et al. observed that when $S$. boulardii was grown with bone marrowderived DCs from CD or ulcerative colitis (UC) patients, there was a reduced concentration of TNF- $\alpha$ and an increase of IL- 6 and $\mathrm{IL}-8$ resulting in a negative immune modulation and increased levels of TGF- $\beta$ which could help in epithelial barrier restoration (89). The challenge of $S$. boulardii on DCs derived from PBMCs was followed by a reduction of TNF- $\alpha$ and IL-6 and an increase of IL-10, thus blocking T cell activation and promoting the polarization of naive $\mathrm{T}$ cells towards Treg cells (90).

\section{Anti-Inflammatory Effect of Probiotics Metabolites (Postbiotics)}

Specific molecules produced by probiotics can contribute to the improvement of host health by promoting specific physiological functions, in the same manner of live probiotics, although the precise mechanisms are not completely elucidated.

Postbiotic supernatant collected from probiotic bacterial cultures could be used to achieve an immune modulation without the possible risks related to living microorganisms such as infections in immune-deficient patients. It is well known that the effect of probiotics can be mediated by their metabolites, such as short-chain fatty acid (SCFA) in particular propionate, acetate, and butyrate that may exercise antiinflammatory effects. SCFAs are produced by bifidobacilli, lactobacilli, and several commensal bacteria. These postbiotics exert their action by binding to specific receptors on intestinal epithelial cells. In this way, the NF- $\kappa \mathrm{B}$ pathway, Treg cell suppression, and pro-inflammatory cytokine production by neutrophils and macrophages are inhibited; consequently, the inflammation state is prevented, and an anti-inflammatory effect is produced $(91,92)$. Butyrate may exert a beneficial effect in controlling gut inflammation through the induction of Treg cell differentiation (93). For instance, L. acidophilus CRL 1014, recently studied in the Simulator of Human Microbial Ecosystem reactor, has shown to produce SCFAs (94) while BB. longum SP 07/03 and BB. bifidum MF 20/5 can produce only propionate and acetate (95).

Additionally, an anti-inflammatory effect may be obtained by the interaction with tryptophan (deriving from diet) and indolic acid derivatives (produced by probiotics or intestinal bacteria) with specific receptors expressed on immune cells. All of these molecules have a role in gut homeostasis; in particular, indole-3propionic acid (IPA) significantly promotes IL-10 production with anti-inflammatory activity and decreases TNF- $\alpha$ release. Both in vitro and in vivo murine studies have shown how $C$. sporogenes can convert tryptophan into IPA, resulting in a protective effect against dextran sulfate sodium-induced acute UC (96).

In other studies, the whole supernatants from probiotic cultures were collected, looking for the sets of regulatory molecules that might induce in immune cells. L. reuteri 17938 is widely used as an adjuvant in infection-associated diarrhea, NEC, and IBD. L. reuteri derived supernatant mixed with PBMCs induced CCR7 on DC membranes as well as the production of FOXp3 and IL-10 in Treg cells (68). De Marco et al. found that $L$. acidophilus and $L$. casei supernatant may reduce the TNF- $\alpha$ release and stimulate IL-10 secretion. Furthermore, L. casei supernatants may inhibit LPS-induced IL-1 $\beta$ activation, which could explain its positive action in IBD (73).

\section{Animal Studies}

A plethora of studies on the role of probiotics on inflammation has been performed in animals and most of these in colitisinduced murine models.

Based on the in vitro studies, L. reuteri LMG P-27481 was orally administered in mice with $C$. difficile induced colitis. This strain obtained brilliant results in reducing $C$. difficile colonization and toxin load; it was able to induce an antiinflammatory response and the restoration of mucosal barrier function resulting in a general improvement of the histologic lesions. The authors speculate that the distinctive features of this strain might be due to the production of bioactive molecules such as exopolysaccharide and peptidoglycan hydrolases. L. reuteri LMG P-27481 might be useful as an adjuvant in C. difficile infection and other inflammatory diseases; however, further studies are needed to support its use in clinical practice (76). Park et al. showed that, in a dextran sulfate sodium-induced colitis, mice fed with $L$. acidophilus showed an increase in Treg cells and splenic IL-10 coupled with a reduction of splenic IL-17 and colonic IL-6, TNF- $\beta$, IL- $1 \beta$, and IL-17 (97). In a recent study, the administration of $L$. fermentum CQPC04 significantly inhibited pro-inflammatory cytokines production (IFN- $\gamma$, IL$1 \beta$, TNF- $\alpha$, IL-6, and IL-12), and promoted the release of IL10 in serum ameliorating the colonic damage (98). Choi et al. demonstrated that the oral administration of L. plantarum strain CAU1055 significantly decreased the levels of inducible NOS, COX-2, TNF- $\alpha$, and IL-6 (99). At the intracellular level, decreased phosphorylation of STAT3, leading to suppression of IL-17 and TNF- $\alpha$ and, consequently, of IL-23/Th17 axis, was demonstrated following administration of L. acidophilus to mice with UC (100). In a study on the trinitrobenzene (TNBS) model of colitis, L. reuteri ATCC PTA6475 was able to reduce inflammation through the histamine $\mathrm{H} 2$-receptor signaling (101). Besides, in research on colitis mice, Qiu et al. (102), Rodríguez-Nogales et al. (103), and Kanda et al. (104) showed that probiotics enhanced Th0 cell differentiation to Treg cell and up-regulated IL-10 secretion. L. rhamnosus RC007 was studied both in healthy and in TNBS-induced-colitis mice. In the first there was an improvement in the phagocytic activity of peritoneal macrophages. At the same time, in the latter there was a reduction of body weight loss and an improvement of macroscopic and microscopic colonic injury. In both cases, an increase in IL-10/TNF $\alpha$ ratio in the intestinal fluids was found (105). Thakur at al. found that L. casei Lbs2 was able to stimulate Treg cells in an experimental mouse model of colitis with an improvement of the severity of the disease (66). A specific strain 
of $L$. plantarum C88 seems to exert a protective mechanism on liver injury in mice: it down-regulates the levels of IL-8, IL-1 $\beta$, IL-6, IFN- $\gamma$ and TNF- $\alpha$ and inhibits the NF- $\kappa$ B signaling pathways reducing TLR2 and TLR4 expression (106).

Yang et al. studied the effect of a probiotic mixture (BB. breve DM8310, Streptococcus thermophiles DM8309, L. casei DM8121, and L. acidophilus DM8302) on the 5-fluorouracil (5-FU) induced enteropathy. The authors report a positive effect of this mixture and speculate that the possible mechanism could be related to the alteration of the TLR2/TLR4 signaling pathways and the restoration of gut homeostasis. This study shed light on the potential mechanism behind their action in chemotherapyinduced intestinal mucositis (107).

In mice with colorectal cancer induced by dimethylhydrazine, treatment with oral $B B$. infantis suppresses CD4+IL-17+ cells and the secretion of IFN- $\gamma$, IL-12, and IL-2 from Th17 and Th1 cells, improving mucositis induced by chemotherapy (108).

Good et al. studied L. rhamnosus HN001 in NEC-induced mice showing the following positive results: a) when administered this probiotic was not responsible for sepsis (a concern in premature newborns); b) its use, alive or UV-killed, resulted in an improvement in the gross aspect of the gut, lower histology score and attenuation of mucosal cytokine levels with the production of inducible NOS (82). In a different murine model of colitis, the administration of L. reuteri 100-23 associated with a diet enriched in tryptophan was able to repolarize gut intraepithelial CD4+ $\mathrm{T}$ cells- into Treg cells enhancing immunotolerance (109).

A summary of the mechanisms of probiotics on in-animal models is displayed in Table 2.

\section{Examples of Anti-Inflammatory Effects of Probiotics In Vivo: From Celiac Disease to Parkinson's Disease}

The anti-inflammatory effect of different strains of probiotics, shown in in vitro and animal studies, must pass the test of "the real-life condition" to assess their potential use in clinical trials. In the following section, we exploit the potential favorable effects of specific probiotic strains as adjuvants in the treatments of ICD, such as CeD, IBD, IBS, obesity, autism, and Parkinson's Disease (PD) among others.

\section{Celiac Disease}

$\mathrm{CeD}$ is an autoimmune enteropathy that occurs in genetically predisposed individuals after gluten ingestion (110). Although gluten is the only well-established trigger in $\mathrm{CeD}$, a dysbiosis mainly characterized by a rise of Bacteroides spp. and a decrease of Bifidobacterium spp (111). has been associated with $\mathrm{CeD}$ in several studies. The intestinal microbiota in this condition has been hypothesized to have a role in $\mathrm{CeD}$ onset, and an international research (the "Celiac Disease Genetic, Environmental, Microbiome, and Metabolomic Analysis") is underway to examine its possible contribution. This study is a prospective, longitudinal observational cohort study of newborns born in a family in which at least one member is affected by CeD, planned to elucidate whether microbiota composition, time of gluten assumption, and genetic asset are implicated in CeD pathogenesis (112).

The only proven effective treatment for $\mathrm{CeD}$ is long-life Gluten-Free Diet (GFD). However, despite strict dietetic adherence, patients often continue to experience gastrointestinal symptoms. The effect of probiotics has been studied as an adjuvant treatment due to its ability to hydrolyze gluten peptides thus reducing their immunogenicity (113) restore gut microbiota, modulate the immune response, and/or reducing the low-grade inflammation, which often does not completely subside after GFD (114). The effects of probiotics in the modulation of immunity (innate and adaptive), and reduction of gliadin-induced inflammation in $\mathrm{CeD}$ are mainly demonstrated by animal models (115-119) and, recently, also in several human studies.

In a recent research, it has been demonstrated that treatment with L. plantarum HEAL9 and L. paracasei 8700:2 $\left(10^{10} \mathrm{CFU} /\right.$ day for six months) can suppress $\mathrm{CeD}$ autoimmunity prior to diagnosis and GFD. In this study, the authors showed a different $\mathrm{T}$ cell modulation between the control group and the probiotic group, associated with a lower titers of anti-tissue transglutaminase-IgA in the probiotic group ( $\mathrm{p}=0.013)(120)$. Klemenak et al. randomized $49 \mathrm{CeD}$ pediatric patients on $\mathrm{GFD}$, to receive either $B B$. breve strains $\mathrm{BR} 03$ and $\mathrm{B} 632\left(2 \times 10^{9} \mathrm{CFU} /\right.$ day $)$ or placebo and demonstrated that three months administration of probiotic leads to lower levels of TNF- $\alpha$; however, TNF- $\alpha$ levels increased again three months after completion of the intervention (121). The same effect on TNF- $\alpha$ level has been confirmed by Primec et al. who studied the impact of a combination of two $B B$. breve strains for three months (daily dose: $2 \mathrm{~g}$ of DSM 16604 and DSM 24706 in a 1:1 ratio) in $40 \mathrm{CeD}$ patients. Besides the positive effect of TNF- $\alpha$, the probiotic combination was followed by a restoration of the Firmicutes/Bacteroidetes ratio (122). Similarly, BB. longum CECT 7347 ( $10^{9} \mathrm{CFU}$ for ninety days along with GFD) has a positive effect on TNF- $\alpha$ levels in CeD patients. This strain determined a reduction of activated $\mathrm{T}$ lymphocytes, a decrease of Bacteroides fragilis and secretive IgA content in stools as compared to placebo (123). The same group studied the efficacy of this strain in rats weaned with gliadins. The authors showed that the treatment with BB. longum CECT $7347\left(6.0 \times 10^{7}-\right.$ $8.2 \times 10^{8} \mathrm{CFU} /$ day) partially counteracted the gliadin-induced changes and improved the inflammation as compared with animals fed gliadin alone. In the same study, the effect was less marked when the animals were sensitized with IFN- $\gamma$, probably because of worst gut damage (124).

Our group recently conducted a clinical trial in $109 \mathrm{CeD}$ patients strictly adherent to the diet with IBS-like symptoms randomizing to receive either a mixture of five strains of lactobacilli and bifidobacteria [L. casei LMG 101/37 P-17504 $\left(5 \times 10^{9} \mathrm{CFU} /\right.$ sachet $)$, L. plantarum CECT $4528\left(5 \times 10^{9} \mathrm{CFU} /\right.$ sachet), BB. animalis subsp. lactis Bil LMG P-17502 $\left(10 \times 10^{9}\right.$ $\mathrm{CFU} /$ sachet $), B B$. breve Bbr8 LMG P-17501 $\left(10 \times 10^{9} \mathrm{CFU} /\right.$ sachet), $B B$. breve Bl10 LMG P-17500 $\left(10 \times 10^{9} \mathrm{CFU} /\right.$ sachet $\left.)\right]$ or placebo for six weeks. We were able to demonstrate that this probiotic combination was effective to reduce the severity of IBS symptoms and to modulate microbiota with increased 
TABLE 2 | Animal studies of different probiotic strains effects in modulating inflammation.

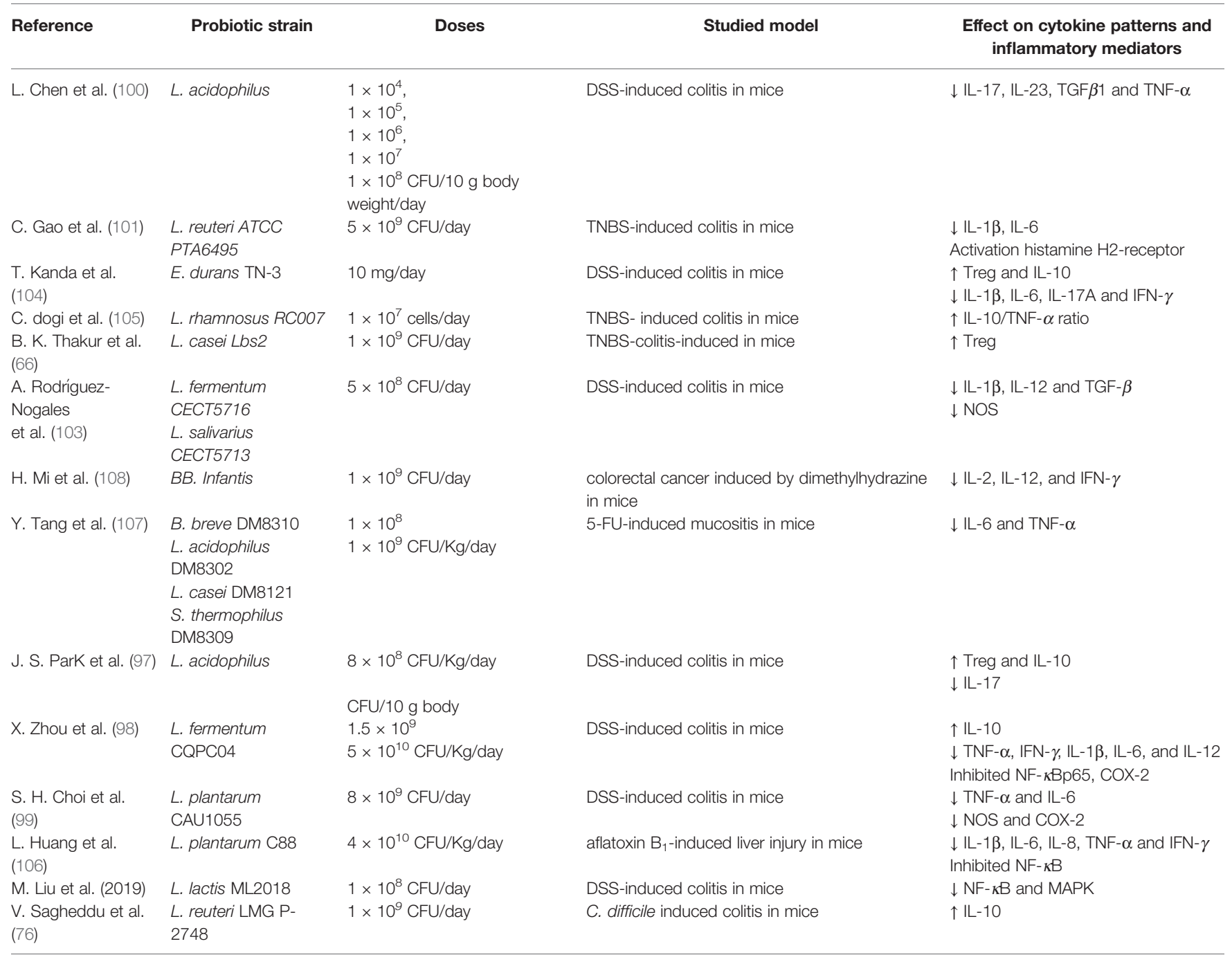

bifidobacteria (125). The ability of the same probiotic combination to hydrolyze gluten has been recently tested in a model of simulated gastrointestinal gliadin digestion. The authors, using CACO-2 cells, showed that physiologicaldigested gliadin could be further hydrolyzed into lower molecular weight peptides by probiotic bacteria. As compared to physiological-digested gliadin, able to induce the synthesis, up-regulation and dissemination of zonulin and occludin by IL6 , the probiotic digested peptides did not show this negative activity (126).

At present GFD is the only proven therapy for $\mathrm{CeD}$ and probiotics, with their ability to modulate intestinal permeability and decrease inflammatory responses, are a safe and promising additional treatment in $\mathrm{CeD}$. In contrast, the possibility of increasing gluten threshold by the concomitant probiotic use, even if attractive, is not yet applicable.

\section{Inflammatory Bowel Diseases}

A theoretical basis for using microbiota driven strategies in IBD was the recognition that a misdirected immune system has a fundamental role in IBD; gut microbiota with its specific genetic makeup and environmental factors have significant contributions in IBD pathogenesis $(127,128)$. Several findings, both on human and animal models, demonstrated the importance of the microbiota-host interaction in both CD and UC. Indeed most IBD patients compared with healthy subjects present a deep dysbiosis with lower diversity, a decrease of antiinflammatory taxa, increased Proteobacteria (such as E. coli and Klebsiella), Ruminococcus gnavus, Pasteurellaceae, Fusobacteria, Candida tropicalis and Veillonellaceae and reduced amount of Firmicutes (especially the potentially protective Faecalibacterium prausnitzii), Bifidobacterium, Ruminococci, and Clostridium (129-131). The increased gut permeability, typical of IBD patients, facilitates translocation of different bacteria through the intestinal layer (132). The interplay between microbiota and receptors on epithelial cells leads to a chronic inflammation responsible for worsening of the disease (133).

UC is a colonic inflammatory disease with an incidence of 10 20 per 100,000 people (134) characterized by a diffuse inflammation, limited to the colon which starts at the rectum 
and spreads proximally. UC pathogenesis is multifactorial and includes a strong genetic predisposition, mucosal immunity and epithelial barrier dysregulation as well as dysbiosis (135).

A recent Cochrane meta-analysis, including 14 studies (865 randomized participants; 12 adults and two pediatric studies) explored the role of probiotics in inducing remission in people with UC. A single strain probiotic was tested in half of the included studies; among those, we found Escherichia coli strain Nissle 1917 (EcN) (136), L. reuteri ATCC 55730 (137) and BB. 536 (138). The other seven trials tested multiple strain combinations. The authors concluded that: 1) probiotics might improve the induction of clinical remission if compared to placebo; 2) there is no difference in remission inducing between probiotics and 5-aminosalicylic acid (5-ASA) (139). In the maintenance of UC remission L. rhamnosus GG (140), EcN (141, 142), the yeast strain S. boulardii (143) and VSL\#3 (144, 145 ) are the most studied strains compared to 5-ASA. Souza et al. evaluated the role of $\mathrm{EcN}$ in mice with colitis: their results showed downregulation of inflammation, lower levels of neutrophils, eosinophils, chemokines, and cytokines. The authors demonstrated an increase of Treg in Peyer's patches associated with an improvement in clinical and histological disease scores. In the same study, germ-free mice transplanted with feces from mice treated with EcN were protected from DSSinduced colitis (146). A large trial performed by Kruis et al. in 2004 evaluated the efficacy of EcN administration in 327 adults with UC in remission. One hundred sixty-two patients received the probiotic ( $200 \mathrm{mg}$ once daily), while 165 were treated with Mesalazine (1,500 mg per day for 12 months). No difference was found in the relapse of patients treated with $\mathrm{EcN}$ as compared to those treated with mesalazine (33.9 vs. 36.4\%) (147). The results of a recently published Cochrane metanalysis are less encouraging. The authors included 12 studies $(1,473$ randomized participants, mostly adults) aimed to compare probiotics vs. placebo, probiotics vs. 5-ASA and a probiotics mixture plus 5-ASA vs. 5-ASA alone. Seven studies focused on a single bacterial strain and five studies on multiple strains. The conclusion was that at present, it is not possible to state if probiotics are able to maintain clinical remission in any of the associations studied (148).

Pouchitis is defined as inflammation within the ileal reservoir and is present in up to $60 \%$ of UC patients who undergo an ilealpouch anal anastomosis. One of the most relevant effects of probiotics in IBD has been obtained in patients with this condition. Forty patients were randomized to receive either 6 $\mathrm{g} /$ day of VSL\#3 or placebo immediately after an ileal-pouch anal anastomosis and were then followed-up for one year: only $10 \%$ of VSL\#3 patients $v s 40 \%$ of placebo developed acute pouchitis. The conclusion was that VSL\#3 is effective in pouchitis prevention (149). Moreover, two RCTs have demonstrated that VSL\#3 is also useful in patients with acute pouchitis for maintaining remission. Patients on VSL\#3 had no relapse as compared to $6 \%$ in patients treated with placebo $(150,151)$. Git VSL\#3 treatment led to a decrease in pro-inflammatory cytokines, increase in Treg cells (152), reduced permeability, and gut microbiota modulation (153).
$\mathrm{CD}$ is a chronic inflammatory disease that can occur in any segment of the gastrointestinal tract characterized by massive inflammation that is typically segmental, asymmetrical, and transmural. The possible beneficial effect of probiotics arises from the different possible mechanisms of action: 1) balance in the composition of the gut microbiota, 2) inhibition of enteric pathogens, 3) degradation of bacterial antigens, 4) blockade of inflammatory mediators, and 5) stimulation of local immunity. Compared to UC, in CD gut microbiota is unstable with a decrease of butyrate-producing bacteria species such as Faecalibacterium, Methanobrevibacter, Christensenellaceae, and Oscillospira. Manichanh et al. demonstrated, in CD patients, an increase in Bacteroidetes and Firmicutes ratio compared to the general population (154). The composition of gut microbiota seems to be influenced by the inflammation site: patients with colitis presented an increase in Firmicutes, while those with ileitis presented a lower diversity (155). One-third of CD patients presented an increased number of mucosaassociated adherent-invasive E. coli; these strains can cross the mucosal layer causing high amounts of TNF- $\alpha$ production (156, 157). Several meta-analyses report few or no effect of probiotics with exception limited to the prevention/treatment of paucities $(158,159)$.

Because of the limited-certainty evidence it is not possible to draw firm conclusions on the potential effect of any specific probiotic strain (or combinations) in reducing clinical relapse or inducing remission in IBD patients. The lack of evidence of probiotic efficacy in IBD could be related to the failure in identifying the ideal strain (or combinations), to possible protocol of treatment bias or because the intervention is started too late in the course of the disease when the 'pathogenic' microbiota is already established.

\section{Irritable Bowel Syndrome}

IBS is one of the most frequent functional gastrointestinal disorders, with an estimated prevalence of approximately $11 \%$ in adults and from 1 to $5 \%$ in children. Recurrent abdominal pain, changes in bowel habits, abdominal distention $(160,161)$ are the most frequent symptoms of IBS. The etiology is still poorly understood but seems to be multifactorial and includes altered intestinal motility, visceral hypersensitivity, abnormal gut-brain interaction, dysbiosis, and low-grade inflammation. In IBS, gastrointestinal dysbiosis has been linked to an increased mucosal permeability interfering with intestinal homeostasis and thereby increasing low-grade gut inflammation and stimulating cellular and mucosal immune activation (162). It has also been speculated that microbiota alteration can affect gut motility and lead to enteric nervous system dysregulation (163). Even though gut microbiota alterations seem to be crucial in IBS, no uniform gut microbiota pattern has yet been demonstrated. The existing inconsistencies among currently available data may be attributed to several factors, including heterogeneity of gut microbiota study methods and individual microbiota variability.

Recently, Tap J et al. have proposed a microbiota signature related to IBS severity in adults, characterized by low microbial richness, lack of Methanobacteriales and Prevotella and increase 
Bacteroides (164). A meta-analysis performed on 13 studies involving 360 IBS patients and 268 healthy controls demonstrated a decrease in the abundances of Lactobacillus, Bifidobacterium, and Faecalibacterium prausnitzii (165). In a recent systematic review of 22 articles, Lactobacillaceae, Enterobacteriaceae, and Bacteroides were more abundant while, uncultivated Faecalibacterium, Clostridiales, and Bifidobacterium were reduced in IBS patients (166).

Studies performed on intestinal biopsies of subjects with postinfective IBS have demonstrated an increase in lymphocytes, mast cells, and inflammatory cytokine possibly related to a dysbiotic microbiota $(167,168)$. Recently Kim et al. studied the effect of a probiotic multistrain mixture $\left(5 \times 10^{9}\right.$ viable cells Bifidobacterium longum BORI, Bifidobacterium bifidum BGN4, Bifidobacterium lactis AD011, Bifidobacterium infantis IBS007, and Lactobacillus acidophilus AD031 three times per day for eight weeks) in patients with diarrhea-predominant IBS, using a metabolomic approach. The authors were able to demonstrate that this probiotic mixture improves IBS symptoms and modifies the levels of urinary metabolites related to gut inflammation (169). O'Mahony et al. performed a clinical trial in 77 IBS patients reporting an abnormal IL-10/IL-12 ratio at baseline, suggestive of a pro-inflammatory state. The patients were randomized to receive, for eight weeks, a malted milk drink added either with $L$. salivarius UCC4331 or with BB. infantis 35624 ( $10^{10}$ live bacterial cells each) or with placebo. Only the treatment with $B B$. infantis 35624 resulted in symptom improvement and normalization of the IL-10/IL-12 ratio (170). Finally, a multispecies probiotic combination (25 billion active bacteria L rhamnosus LR5 $3 \times 10^{9}$ CFU; L. casei LC5 $2 \times 10^{9}$ CFU; L. paracasei LPC5 $1 \times 10^{9}$ CFU; L. plantarum LP3 $1 \times$ $10^{9}$ CFU; L. acidophilus LA1 $5 \times 10^{9}$ CFU; BB. bifidum BF3 $4 \times$ $10^{9} \mathrm{CFU} ; \mathrm{BB}$. longum BG7 $1 \times 10^{9} \mathrm{CFU}$; BB. breve BR3 $2 \times 10^{9}$ CFU; BB. infantis BT1 $1 \times 10^{9} \mathrm{CFU}$; S. thermophilus ST3 $2 \times 10^{9}$ CFU; L. bulgaricus LG1; and Lactococcus lactis SL6 $3 \times 10^{9} \mathrm{CFU}$ ) was used to test the possibility to reduce inflammation in IBS patients. One-hundred-seven patients were randomized to the probiotic mixtures (two times a day) or placebo: after eight weeks of treatment, no difference was found in IBS symptoms score, in fecal calprotectin level and high sensitivity $C$ reactive protein between the two groups (171).

Several meta-analyses demonstrate the positive effect of probiotics (single strains and multistrain) in the management of IBS $(172,173)$ although a single strain or combination has not been definitively identified. The beneficial effect is related to the immune-modulating effect of probiotics on the regulation of anti-inflammatory/pro-inflammatory cytokines that cannot be exclusive of a particular species (170, 174-176).

We recently reviewed the guidelines published by several scientific societies on probiotics in IBS and concluded that in adults, taken as a group, probiotics could ameliorate global symptoms; however, at present no recommendations regarding individual species, preparations, or strains can be made because of limited and conflicting data. In pediatric IBS, current evidence shows efficacy of L. rhamnosus GG, L. reuteri 17938 and VSL\#3, thus supporting their use (177).

\section{Obesity}

Obesity is defined as excessive/abnormal fat accumulation with adverse health consequences. Obesity and its metabolic complications represent a relevant health problem all over the world. The prevalence of obesity is three times higher since 1975, and more than $13 \%$ of the world's population is obese at present (178). The pathogenesis of obesity is multifactorial and includes hormonal, genetic, and environmental factors. However, growing evidence shows that microbiome influences the energy balance contributing to obesity pathogenesis and its associated complications (179).

Gut microbiota is involved in energy homeostasis by extracting energy from foods through fermentation processes. It has been speculated that the increased energy extraction (especially for plant-derived complex carbohydrates) could have been an advantage in conditions of limited food availability. However, nowadays the increased availability of food and the changes in the proportion of diet components (increased intake of fat and sugar and reduction of plant-derived carbohydrates) can be responsible for a negative effect of our microbiota on human health (180).

It has been reported that the Firmicutes to Bacteroidetes ratio is altered in obese people, and this seems to promote the energy extraction from foods and storage (181). Changes in the intestinal microbiota in response to weight-reducing diets have also been documented (182). On the contrary, gut microbiota alterations can be associated with increased obesity risk (183). A meta-analysis showed that a reduced count of Bifidobacterium during early infancy is more often found in obese children as compared to normal weight controls (184).

A developing term in the field of innate immunology is that of metabolic endotoxemia. Metabolic endotoxemia is described as a subclinical increase in circulating endotoxin levels that although not noticeable in clinical settings, plays a significant role in the etiology for many chronic diseases. Several studies have shown an alteration of the intestinal permeability that may potentially trigger the metabolic endotoxemia. Once in the circulation LPS bind to LPS-binding protein promoting the activation of inflammatory pathways, including NF- $\kappa \mathrm{B}$ and subsequent cytokine release such as IL- 6 and TNF- $\alpha$, that in turn lead insulin resistance in several tissues (185). It has been hypothesized that targeted microbiota interventions might be used for the prevention and treatment of obesity and associated metabolic conditions (186). The demonstrated effect of probiotics in the regulation of intestinal permeability is an attractive option and worth considering further, especially at the light of data from animal studies where probiotics have shown the ability to improve intestinal permeability and metabolic and inflammatory status $(187,188)$.

Different authors have shown that some strains of Bifidobacterium and Lactobacillus can prevent obesity across several studies in animals and human, including L. rhamnosus, L. casei, L. plantarum, L. gasseri, BB. infantis, BB. longum, and $B B$. breve (189). The administration of $L$. plantarum TN8 can induce an increase of anti-inflammatory IL-10 levels as well as a decrease in pro-inflammatory IL-12, IFN- $\gamma$, and TNF- $\alpha$ in diet- 
induced obese mice (190). Miyoshi et al. performed a study in mice evaluating the effect of L. gasseri SBT2055; they showed that L. gasseri significantly influenced fat accumulation, reduced weight gain, and modulated adipose tissue pro-inflammatory cytokines (191).

Park et al. performed a study in diet-induced obese mice on the effect L. curvatus HY7601 and L. plantarum KY1032 $(5 \times$ $10^{9} \mathrm{CFU} /$ day for more than two months): probiotics decreased fat accumulation and reduced BMI. Moreover, the authors observed that, in mice receiving probiotic treatment, proinflammatory genes in the adipose tissue (IL1 $\beta$, TNF- $\alpha$, IL6, and monocyte chemotactic protein-1) were downregulated. In contrast, fatty acid oxidation-related genes were upregulated in the liver (192). One month administration of S. boulardii in obese and type 2 diabetic mice has been shown to reduce obesity, hepatic steatosis, fat mass, and inflammation with a concomitant effect on gut microbiota composition (increased in Bacteroidetes and a decreased in Firmicutes, Proteobacteria, and Tenericutes) (193).

Bernini et al. showed that BB. lactis HN019 (80 ml of the probiotic milk containing on average $3.4 \times 10^{8} \mathrm{CFU} / \mathrm{ml}$ ) in patients with metabolic syndrome led to reduced weight gain and modulation of cytokines such as IL- 6 and TNF- $\alpha$ (194). The supplementation with $L$. reuteri V3401 $\left(5 \times 10^{9} \mathrm{CFU}\right.$ for three months) in patients with metabolic syndrome resulted in IL-6 and soluble vascular cell adhesion molecule 1 (sVCAM-1) decrease associated with a rise in the proportion of Verrucomicrobia (195).

Several systematic reviews and meta-analyses evaluating the role of probiotics in obesity have been published, and most of them have shown a BMI decrease in enrolled patients who were supplemented with several probiotics strains $(196,197)$; however, other trials failed to demonstrate this effect. Recently the effects of prophylactic $B B$. lactis $\mathrm{BS} 01$ and L. acidophilus LA02 supplementation $\left(2 \times 10^{9} \mathrm{CFU}\right.$ for six weeks) were studied. On anthropometric measures in healthy, young females: no significant effects were found on all anthropometric measurements (198).

Given the current epidemic of obesity plaguing Western society, a call is necessary for feasible, available, and safe treatments to prevent and fight against it. Even though obesity pathogenesis is multifactorial and highly complicated, recent literature suggests microbiota alterations as the primary contributor to its development and associated metabolic and inflammatory abnormalities. Consequently, gut microbiome modulation to preserve a stable, consistent metabolic environment may be helpful in preventing and as additional treatment in obese people.

\section{Autism}

ASDs are a variety of developmental disabilities that usually appear in the first few years of life and manifest in several ways with different grades of severity from mild impairment to complete inability to live an adequate social and personal life. The incidence of ASD is increasing, although it is still unknown if this is secondary to an increase in social awareness and earlier diagnosis or to a real rise in prevalence secondary to modified environmental conditions (199). The etiology is still unknown: genetic, epigenetic, environmental, and infectious factors have been identified as possible cofactors that enter in the pathogenesis of this multifactorial disorder. It is well established that there is a strong connection between the brain and gut: the so-called brain-gut axis. This connection implies that these two organs, although so different, influence each other's development and function. In particular intestinal microbiota is able to send signals to the central nervous system via intestinal epithelial, bowel neuronal and immune cells. Germ-free mice develop different alterations of neurotransmitter turnover, neuroinflammation, neurogenesis, and neuronal morphology (200). In ASD patients, the intestinal microbiota is altered: as compared to healthy peers higher concentrations of pathogenic Clostridium bacteria (201), a decreased Bacteroides/Firmicutes ratio, and increased Lactobacillus and Desulfovibrio species $(202,203)$ have been shown. This altered microbiota creates an inflammatory environment with the release of cytokines leading to a disruption of the mucosal barrier functions.

It has been reported that alterations in cytokine levels and immune dysregulation are frequent in ASD patients. IL-6, macrophage chemoattractant protein- 1 and TNF- $\alpha$ play a role in cerebral inflammation (204) and a higher concentrations of these chemokines along with IFN- $\gamma$, IL- $1 \beta$, are present in ASD patients (205). In a murine model of ASD, de Theije C et al. investigated the relationship between gut microbiota and autismlike behavior in mice in utero exposed to valproic acid. As expected, the authors demonstrated a change in the Firmicutes and Bacteroidetes phyla in the offspring supporting that an intestinal phenotype is associated with autism-like behavior with preponderance in male offspring and associated with boosted levels of cecal butyrate and ileal neutrophil infiltration and inversely correlated with serotonin gut levels (206).

In a recent study performed in an animal model of obsessivecompulsive disorder, the effects of $L$. casei Shirota consumption has been studied. Behavioral tests demonstrated the reduction of obsessive-compulsive disorder symptoms in mice after $L$. casei Shirota treatment, and the authors demonstrated that this is secondary to the regulation of serotonin-related genes expression (207). In a randomized placebo-controlled double-blind study, ASD children were treated with $L$. plantarum WCSF1 for three months. An increase in enterococci and lactobacilli and a reduction in Clostridium cluster XIVa were found. This resulted not only in an improvement of the intestinal symptoms but, more importantly, in an increase in behavioral scores (208). By treating ASD children, their siblings and neurotypical children with a mixture of probiotics (Lactobacillus, Bifidobacterium and Streptococcus strains) for four months, Tomova et al. found a decrease in TNF- $\alpha$ levels, a primary inflammatory cytokine, reduced Bifidobacterium and Desulfovibrio spp., and also reestablished the Bacteroidetes/Firmicutes ratio (203).

De Angelis et al. address the issue using the metabolomic approach. In particular, they found that ASD patients have: 1) an increase in fecal free amino acids which correlates with an increase in the gut colonization of proteolytic bacteria such as Clostridia (except for C. Barletti) and Bacteroides, 2) an alteration in fecal volatile organic compounds suggestive of 
intestinal dysbiosis, 3) the presence of peptides (indoles and phenols compounds) that play as pseudo-neurotransmitters and neuromodulators, responsible for a reduction in neuroplasticity development and 4) a reduction of SCFAs (such as butyric acid) able to influence neuronal activity and contributing to the socalled "leaky gut" already demonstrated in these patients. The authors also noted an association between the variability of the alterations found and the degree of disease severity: gut dysbiosis is more pronounced in ASD children with significant deficits as compared to pervasive developmental disorder not otherwise specified $(209,210)$.

ASD involve multiple disabilities with multifactorial etiologies which implies that it must be treated with a holistic approach by a multidisciplinary team. A better understanding of the gut-brain axis in ASD may help clinicians in treating gastrointestinal dysbiosis as soon as possible because this may improve behavioral and cognitive skills. Of course, further studies are needed to understand which specific probiotic or evidence-based nutritional advice should be used according to the patient's intestinal condition.

\section{Parkinson's Disease}

$\mathrm{PD}$ is a common degenerative neuromotor disorder affecting 1-2 per 1,000 people worldwide (211). The pathogenesis is multifactorial, and the pathological hallmarks in PD are Lewy body, presence of intraneuronal aggregated alpha-synuclein, and progressive loss of dopaminergic neurons in the substantia nigra compacta. The typical clinical symptoms include bradykinesia, postural instability, and tremor but also gastrointestinal symptoms tract such as constipation and bloating. Moreover, in PD patients, evidence of inflammatory changes has been reported in the brain parenchyma (increased levels of pro-inflammatory cytokines and $\mathrm{T}$ cell infiltration) and enteric nervous system.

The gut involvement in PD including increased gut permeability (212) and the presence of gastrointestinal symptoms and inflammation (213) have led to the hypothesis that gut microbiota may have an influence in $\mathrm{PD}$ pathogenesis such as in alpha-synuclein aggregation. Recently, an increase in opportunistic pathogens and SCFA-producing bacteria and a decrease in carbohydratemetabolizing bacteria in PD patients has been demonstrated. The most consistent microbiota changes that can constitute a specific microbial signature of PD are: 1) decrease of Prevotellaceae, 2) increase of Verrucomicrobiaceae and Akkermansia, 3) increased abundance of Bifidobacteria and 4) decreased abundance in Lachnospiraceae (214). Several studies in vitro and animal models demonstrated the efficacy of specific probiotic strains in modulating the inflammation in PD.

Magistrelli et al. demonstrated, in an in vitro model using PD patients' PBMCs co-cultured with a selection of probiotic microorganisms belonging to the Lactobacillus and Bifidobacterium genus, that expression of the pro-inflammatory cytokines IL-1, IL-8, and TNF- $\alpha$ was reduced. In contrast, the expression of the antiinflammatory regulators TNF- $\beta$ was increased (215). The administration of a probiotic mixture (Lactobacillus and Bifidobacterium) in two toxin-induced mouse models of PD improved the degeneration of substantia nigra dopaminergic cells and reduced the motor decline by increasing butyrate production, which inhibited nigral inflammation (216).

The main clinical trial on the use of probiotics in PD has been conducted by Tamtaji et al. The authors randomized 60 PD patients to receive either a multistrain probiotic (containing Lactobacillus and Bifidobacterium) or placebo and demonstrated an improvement in motor signs and symptoms in the probiotic treated group. The clinical effect was associated with higher levels of the antioxidant glutathione and reduced serum levels of C-reactive protein (217).

Pharmacotherapy options for PD are limited at present, and safe non-invasive therapeutic options are needed; this is the reason why probiotics represent an attractive option. However, no solid clinical data are yet available on the real efficacy of this new therapeutic option on motor symptoms and the progression of $\mathrm{PD}$.

\section{CONCLUSION}

Recently, extensive pieces of evidence are available on local intestinal and systemic immune responses, describing the complicated relationship between foods, bacteria, derived metabolites, and the immune system. The intestinal microbiota, as stated in this review, seems to be primarily involved in the pathogenesis of various ICD characterized by a robust gene-environment interaction. Several bacterial species within the gut are identified as talented players for the onset or maintenance of these conditions. A new approach to ICD will focus on the plethora of factors that may play a role in the vast and still undiscovered world of chronic inflammation that stems from an imbalance of intestinal microbiota: the gut as a door to the body. Restoring what Nature has created and shaped during human evolution and men have changed so dramatically in a couple of centuries is a utopic task. We are now just at the beginning of the understanding of the intimate mechanisms regulating the coevolution of men and microbes. After more than twenty years of research it has appeared clear that each probiotic strain even from the same probiotic species can behave differently according to its specific metabolic pathways, the amount of administered probiotic, the interaction between probiotics and the host, the host itself and its microbiota, the diet, duration of the treatment and all other possible variables. Unfortunately, to have real clinical data that can be replicated and verified, everything needs to be standardized, which is a titanic feat.

Medicine is going toward individualization, and this is also the case of probiotics. In the future, each probiotic treatment will be adapted to the specific patient in that particular clinical situation. Further studies are needed regarding every single aspect of the probiotic therapy, and hopefully, we will reach a robust, patient-tailored biological treatment.

\section{AUTHOR CONTRIBUTIONS}

All authors contributed to the article and approved the submitted version. All authors take full responsibility for the manuscript. 


\section{REFERENCES}

1. Prescott SL. Early-life environmental determinants of allergic diseases and the wider pandemic of inflammatory noncommunicable diseases. J Allergy Clin Immunol (2013) 131(1):23-30. doi: 10.1016/j.jaci.2012.11.019

2. Ke X. Presence of multiple independent effects in risk loci of common complex human diseases. Am J Hum Genet (2012) 91(1):185-92. doi: 10.1016/j.ajhg.2012.05.020

3. Crimmins EM, Finch CE. Infection, inflammation, height, and longevity. Proc Natl Acad Sci U.S.A. (2006) 103(2):498-503. doi: 10.1073/ pnas. 0501470103

4. Barrett R, Kuzawa CW, McDade T, Armelagos GJ. Emerging and reemerging infectious diseases: the third epidemiologic transition. Emerg Re-emerg Infect Dis: Third Epidemiol Transition (1998) 12(6):778-87. doi: 10.1146/annurev.anthro.27.1.247

5. Lochmiller RL, Deerenberg C. Trade-offs in evolutionary immunology: Just what is the cost of immunity? Oikos (2000) 88(1):87-98. doi: 10.1034/j.16000706.2000.880110.x

6. McDade TW. Life History Theory and the Immune System: Steps Toward a Human Ecological Immunology. Am J Phys Anthropol (2003) 122:100-25. doi: 10.1002/ajpa.10398

7. Gurven M, Kaplan H, Winking J, Finch C, Crimmins EM. Aging and inflammation in two epidemiological worlds. J Gerontol Ser A Biol Sci Med Sci (2008) 63(2):196-9. doi: 10.1093/gerona/63.2.196

8. Lisciandro JG, Van Den Biggelaar AHJ. Neonatal immune function and inflammatory illnesses in later life: Lessons to be learnt from the developing world? Clin Exp Allergy (2010) 40:1719-31. doi: 10.1111/j.13652222.2010.03629.x

9. Rook GAW, Brunet LR. Give us this day our daily germs. Biologist (2002) 49:145-9.

10. Yazdanbakhsh M, Kremsner PG, Van Ree R. Immunology: Allergy, parasites, and the hygiene hypothesis. Science (2002) 296:490-4. doi: 10.1126/science.296.5567.490

11. Radon K, Windstetter D, Poluda AL, Mueller B, Von Mutius E, Koletzko S, et al. Contact with farm animals in early life and juvenile inflammatory bowel disease: A case-control study. Pediatrics (2007) 120(2):354-61. doi: 10.1542/peds.2006-3624

12. Martin R, Nauta AJ, Ben Amor K, Knippels LMJ, Knol J, Garssen J. Early life: Gut microbiota and immune development in infancy. Benef Microbes (2010) 1(4):367-82. doi: 10.3920/BM2010.0027

13. Rook GAW, Adams V, Hunt J, Palmer R, Martinelli R, Brunet LR. Mycobacteria and other environmental organisms as immunomodulators for immunoregulatory disorders. Springer Semin Immunopathol (2004) 25:237-55. doi: 10.1007/s00281-003-0148-9

14. McFall-Ngai M. Adaptive immunity: Care for the community. Nature (2007) 445:153. doi: $10.1038 / 445153$ a

15. Macpherson AJ, Uhr T. Induction of Protective IgA by Intestinal Dendritic Cells Carrying Commensal Bacteria. Sci (80- ) (2004) 303(5664):1662-5. doi: $10.1126 /$ science. 1091334

16. Atarashi K, Tanoue T, Shima T, Imaoka A, Kuwahara T, Momose Y, et al. Induction of colonic regulatory $\mathrm{T}$ cells by indigenous Clostridium species. Sci (80- ) (2011) 331(6015):337-41. doi: 10.1126/science.1198469

17. Round JL, Lee SM, Li J, Tran G, Jabri B, Chatila TA, et al. The toll-like receptor 2 pathway establishes colonization by a commensal of the human microbiota. Sci (80- ) (2011) 332(6032):974-7. doi: 10.1126/science.1206095

18. Kieper WC, Troy A, Burghardt JT, Ramsey C, Lee JY, Jiang H-Q, et al. Cutting Edge: Recent Immune Status Determines the Source of Antigens That Drive Homeostatic T Cell Expansion. J Immunol (2005) 174(6):3158 -63. doi: 10.4049/jimmunol.174.6.3158

19. Abraham C, Cho JH. IL-23 and Autoimmunity: New Insights into the Pathogenesis of Inflammatory Bowel Disease. Annu Rev Med (2009) 60 (1):97-110. doi: 10.1146/annurev.med.60.051407.123757

20. Lee YK, Menezes JS, Umesaki Y, Mazmanian SK. Proinflammatory T-cell responses to gut microbiota promote experimental autoimmune encephalomyelitis. Proc Natl Acad Sci U.S.A. (2011) 108(SUPPL. 1):4615 -22. doi: 10.1073/pnas.1000082107

21. Wu HJ, Ivanov II, Darce J, Hattori K, Shima T, Umesaki Y, et al. Gutresiding segmented filamentous bacteria drive autoimmune arthritis via
$\mathrm{T}$ helper 17 cells. Immunity (2010) 32(6):815-27. doi: 10.1016/ j.immuni.2010.06.001

22. Renz H, Brandtzaeg P, Hornef M. The impact of perinatal immune development on mucosal homeostasis and chronic inflammation. Nat Rev Immunol (2012) 12:9-23. doi: 10.1038/nri3112

23. Sommer F, Bäckhed F. The gut microbiota-masters of host development and physiology. Nat Rev Microbiol (2013) 11:227-38. doi: 10.1038/nrmicro2974

24. Garn H, Neves JF, Blumberg RS, Renz H. Effect of barrier microbes on organ-based inflammation. J Allergy Clin Immunol (2013) 131:1465-78. doi: $10.1038 /$ nrmicro2974

25. West CE, Jenmalm MC, Prescott SL. The gut microbiota and its role in the development of allergic disease: A wider perspective. Clin Exp Allergy Blackwell Publishing Ltd (2015) 45:43-53. doi: 10.1111/cea.12332

26. Strachan DP. Hay fever, hygiene, and household size. Br Med J (1989) 299 (6710):1259-60. doi: 10.1136/bmj.299.6710.1259

27. Rook GA. Regulation of the immune system by biodiversity from the natural environment: An ecosystem service essential to health. Proc Natl Acad Sci United States America (2013) 110:18360-7. doi: 10.1073/pnas.1313731110

28. Wold AE. The hygiene hypothesisi revised: Is the rising frequency of allergy due to changes in rising the intestinal flora? Allergy Eur J Allergy Clin Immunol (1998) 53(SUPPL. 46):20-5. doi: 10.1111/j.1398-9995.1998. tb04953.x

29. Yatsunenko T, Rey FE, Manary MJ, Trehan I, Dominguez-Bello MG, Contreras $\mathrm{M}$, et al. Human gut microbiome viewed across age and geography. Nature (2012) 486:222-7. doi: 10.1038/nature11053

30. Lozupone CA, Stombaugh JI, Gordon JI, Jansson JK, Knight R. Diversity, stability and resilience of the human gut microbiota. Nature (2012) 489:220 -30. doi: 10.1038/nature11550

31. Fouhy F, Ross RP, Fitzgerald G, Stanton C, Cotter PD. Composition of the early intestinal microbiota:Knowledge, knowledge gaps and the use of highthroughput sequencing to address these gaps. Gut Microbes (2012) 3:203-20. doi: 10.4161/gmic.20169

32. West CE. Gut microbiota and allergic disease: New findings. Curr Opin Clin Nutr Metab Care (2014) 17:261-6. doi: 10.1097/MCO.0000000000000044

33. Francavilla R, Cristofori F, Tripaldi ME, Indrio F. Intervention for Dysbiosis in Children Born by C-Section. Ann Nutr Metab (2018) 73:33-9. doi: $10.1159 / 000490847$

34. Azad MB, Konya T, Maughan H, Guttman DS, Field CJ, Chari RS, et al. Gut microbiota of healthy Canadian infants: Profiles by mode of delivery and infant diet at 4 months. CMAJ (2013) 185(5):385-94. doi: 10.1503/ cmaj.121189

35. Jakobsson HE, Abrahamsson TR, Jenmalm MC, Harris K, Quince C, Jernberg C, et al. Decreased gut microbiota diversity, delayed Bacteroidetes colonisation and reduced Th1 responses in infants delivered by Caesarean section. Gut (2014) 63(4):559-66. doi: 10.1136/gutjnl-2012303249

36. Penders J, Gerhold K, Stobberingh EE, Thijs C, Zimmermann K, Lau S, et al. Establishment of the intestinal microbiota and its role for atopic dermatitis in early childhood. J Allergy Clin Immunol (2013) 132(3):601-607.e8. doi: 10.1016/j.jaci.2013.05.043

37. Karlström A, Lindgren H, Hildingsson I. Maternal and infant outcome after caesarean section without recorded medical indication: Findings from a Swedish case-control study. BJOG Int J Obstet Gynaecol (2013) 120(4):479 -86. doi: 10.1111/1471-0528.12129

38. Kolokotroni O, Middleton N, Gavatha M, Lamnisos D, Priftis KN, Yiallouros PK. Asthma and atopy in children born by caesarean section: effect modification by family history of allergies - a population based crosssectional study. BMC Pediatr (2012) 12:179. doi: 10.1186/1471-2431-12-179

39. Li H, Ye R, Pei L, Ren A, Zheng X, Liu J. Caesarean delivery, caesarean delivery on maternal request and childhood overweight: A Chinese birth cohort study of 181380 children. Pediatr Obes (2014) 9(1):10-6. doi: 10.1111/j.2047-6310.2013.00151.x

40. Stene LC, Gale EAM. The prenatal environment and type 1 diabetes. Diabetologia (2013) 56:1888-97. doi: 10.1007/s00125-013-2929-6

41. Imamura F, Micha R, Khatibzadeh S, Fahimi S, Shi P, Powles J, et al. Dietary quality among men and women in 187 countries in 1990 and 2010: A systematic assessment. Lancet Glob Heal (2015) 3(3):e132-42. doi: 10.1016/ S2214-109X(14)70381-X 
42. Monteiro CA, Moubarac JC, Cannon G, Ng SW, Popkin B. Ultra-processed products are becoming dominant in the global food system. Obes Rev Obes Rev (2013) 14:21-8. doi: 10.1111/obr.12107

43. Mozaffarian D. Dietary and Policy Priorities for Cardiovascular Disease, Diabetes, and Obesity. Circulation (2016) 133:187-225. doi: 10.1161/ CIRCULATIONAHA.115.018585

44. Atkinson FS, Foster-Powell K, Brand-Miller JC. International tables of glycemic index and glycemic load values: 2008. Diabetes Care (2008) 31 (12):2281-3. doi: $10.2337 / \mathrm{dc} 08-1239$

45. Bhupathiraju SN, Tobias DK, Malik VS, Pan A, Hruby A, Manson JE, et al. Glycemic index, glycemic load, and risk of type 2 diabetes: Results from 3 large US cohorts and an updated meta-analysis. Am J Clin Nutr (2014) 100 (1):218-32. doi: 10.3945/ajcn.113.079533

46. Panagiotakos DB, Pitsavos C, Skoumas Y, Stefanadis C. \{A figure is presented\}The Association between Food Patterns and the Metabolic Syndrome Using Principal Components Analysis: The ATTICA Study. J Am Diet Assoc (2007) 107(6):979-87. doi: 10.1016/j.jada.2007.03.006

47. Arumugam M, Raes J, Pelletier E, Le Paslier D, Yamada T, Mende DR, et al. Enterotypes of the human gut microbiome. Nature (2011) 473(7346):174 -80. doi: $10.1038 /$ nature 09944

48. Buc M. Role of regulatory T cells in pathogenesis and biological therapy of multiple sclerosis. Mediators Inflammation (2013) 2013:1-11. doi: 10.1155/ 2013/963748

49. Koeth RA, Lam-Galvez BR, Kirsop J, Wang Z, Levison BS, Gu X, et al. LCarnitine in omnivorous diets induces an atherogenic gut microbial pathway in humans. J Clin Invest (2019) 129(1):373-87. doi: 10.1172/JCI94601

50. Thaiss CA, Levy M, Grosheva I, Zheng D, Soffer E, Blacher E, et al. Hyperglycemia drives intestinal barrier dysfunction and risk for enteric infection. Sci (80- ) (2018) 359(6382):1376-83. doi: 10.1126/science. aar3318

51. Caesar R, Tremaroli V, Kovatcheva-Datchary P, Cani PD, Bäckhed F. Crosstalk between gut microbiota and dietary lipids aggravates WAT inflammation through TLR signaling. Cell Metab (2015) 22(4):658-68. doi: 10.1016/j.cmet.2015.07.026

52. Sommer F, Anderson JM, Bharti R, Raes J, Rosenstiel P. The resilience of the intestinal microbiota influences health and disease. Nat Rev Microbiol (2017) 15:630-8. doi: 10.1038/nrmicro.2017.58

53. Levy M, Kolodziejczyk AA, Thaiss CA, Elinav E. Dysbiosis and the immune system. Nat Rev Immunol (2017) 17:219-32. doi: 10.1038/nri.2017.7

54. Douglas CA, Ivey KL, Papanicolas LE, Best KP, Muhlhausler BS, Rogers GB. DNA extraction approaches substantially influence the assessment of the human breast milk microbiome. Sci Rep (2020) 10(1):123. doi: 10.1038/ s41598-019-55568-y

55. Yang Q, Graham TE, Mody N, Preitner F, Peroni OD, Zabolotny JM, et al. Serum retinol binding protein 4 contributes to insulin resistance in obesity and type 2 diabetes. Nature (2005) 436(7049):356-62. doi: 10.1038/ nature 03711

56. Ng SC, Hart AL, Kamm MA, Stagg AJ, Knight SC. Mechanisms of action of probiotics: Recent advances. Inflammatory Bowel Dis Inflammation Bowel Dis (2009) 15:300-10. doi: 10.1002/ibd.20602

57. Ferlazzo G, Rizzello V, Bonaccorsi I, Dongarr ML, Fink LN. Role of natural killer and dendritic cell crosstalk in immunomodulation by commensal bacteria probiotics. J BioMed Biotechnol (2011) 2011:473097. doi: 10.1155/ 2011/473097

58. Mohamadzadeh M, Olson S, Kalina WV, Ruthel G, Demmin GL, Warfield $\mathrm{KL}$, et al. Lactobacilli active human dendritic cells that skew $\mathrm{T}$ cells toward $\mathrm{T}$ helper 1 polarization. Proc Natl Acad Sci U.S.A. (2005) 102(8):2880-5. doi: 10.1073/pnas.0500098102

59. Fink LN, Zeuthen LH, Christensen HR, Morandi B, Frøkiaer H, Ferlazzo G. Distinct gut-derived lactic acid bacteria elicit divergent dendritic cellmediated NK cell responses response via potent stimulation of IFN-g production in NK cells. Combining IFN-g-inducing and non-inducing LAB completely abrogates DC-mediated IFN-g production by NK cells, and therefore LAB modulating IFN-g production in NK cells may be important regulators of the immune response. Int Immunol (2007) 19 (12):1319-27. doi: 10.1093/intimm/dxm103

60. Blum S, Alvarez S, Haller D, Perez P, Schiffrin EJ. Intestinal microflora and the interaction with immunocompetent cells. In: Lactic Acid Bacteria:
Genetics, Metabolism and Applications. Springer Netherlands (1999) 76(14):199-205. doi: 10.1007/978-94-017-2027-4_9

61. Helwig U, Lammers KM, Rizzello F, Brigidi P, Rohleder V, Caramelli E, et al. Lactobacilli, bifidobacteria and E. coli nissle induce pro- and antiinflammatory cytokines in peripheral blood mononuclear cells. World $J$ Gastroenterol WJG Press (2006) 12(37):5978-86. doi: 10.3748/wjg.v12. i37.5978

62. Medina M, Izquierdo E, Ennahar S, Sanz Y. Differential immunomodulatory properties of Bifidobacterium logum strains: Relevance to probiotic selection and clinical applications. Clin Exp Immunol (2007) 150(3):531-8. doi: 10.1111/j.1365-2249.2007.03522.x

63. Ruemmele FM, Bier D, Marteau P, Rechkemmer G, Bourdet-Sicard R, Walker WA, et al. Clinical evidence for immunomodulatory effects of probiotic bacteria. J Pediatr Gastroenterol Nutr J Pediatr Gastroenterol Nutr (2009) 48:126-41. doi: 10.1097/MPG.0b013e31817d80ca

64. Smits HH, Engering A, Van Der Kleij D, De Jong EC, Schipper K, Van Capel TMM, et al. Selective probiotic bacteria induce IL-10-producing regulatory $\mathrm{T}$ cells in vitro by modulating dendritic cell function through dendritic cellspecific intercellular adhesion molecule 3-grabbing nonintegrin. J Allergy Clin Immunol (2005) 115(6):1260-7. doi: 10.1016/j.jaci.2005.03.036

65. Pan SJ, Kuo CH, Lam KP, Chu Y, Wang WL, Hung CH. Probiotics and allergy in children - An update review. Pediatr Allergy Immunol Pediatr Allergy Immunol (2010) 21:e659-66.

66. Thakur BK, Saha P, Banik G, Saha DR, Grover S, Batish VK, et al. Live and heat-killed probiotic Lactobacillus casei Lbs2 protects from experimental colitis through Toll-like receptor 2-dependent induction of T-regulatory response. Int Immunopharmacol Elsevier B V (2016) 36:39-50. doi: 10.1016/ j.intimp.2016.03.033

67. Eslami S, Hadjati J, Motevaseli E, Mirzaei R, Farashi Bonab S, Ansaripour B, et al. Lactobacillus crispatus strain SJ-3C-US induces human dendritic cells (DCs) maturation and confers an anti-inflammatory phenotype to DCs. APMIS Blackwell Munksgaard (2016) 124(8):697-710. doi: 10.1111/apm.12556

68. Haileselassie Y, Navis M, Vu N, Qazi KR, Rethi B, Sverremark-Ekström E. Postbiotic modulation of retinoic acid imprinted mucosal-like dendritic cells by probiotic Lactobacillus reuteri 17938 in vitro. Front Immunol (2016) 7:96 (MAR). doi: 10.3389/fimmu.2016.00096

69. Johansson MA, Björkander S, Forsberg MM, Qazi KR, Celades MS, Bittmann J, et al. Probiotic lactobacilli modulate Staphylococcus aureusinduced activation of conventional and unconventional T cells and NK cells. Front Immunol (2016) 7:273. doi: 10.3389/fimmu.2016.00273

70. Smith IM, Baker A, Christensen JE, Boekhout T, Frøkiær H, Arneborg N, et al. Kluyveromyces marxianus and Saccharomyces boulardii induce distinct levels of dendritic cell cytokine secretion and significantly different T cell responses in vitro. PloS One Public Library Sci (2016) 11(11):e0167410. doi: 10.1371/journal.pone.0167410

71. Ren C, Zhang Q, De Haan BJ, Zhang H, Faas MM, De Vos P. Identification of TLR2/TLR6 signalling lactic acid bacteria for supporting immune regulation. Sci Rep Nat Publishing Group (2016) 6:34561. doi: 10.1038/ srep34561

72. Compare D, Rocco A, Coccoli P, Angrisani D, Sgamato C, Iovine B, et al. and its postbiotic reduce the inflammatory mucosal response: An ex-vivo organ culture model of post-infectious irritable bowel syndrome. BMC Gastroenterol BioMed Cent Ltd (2017) 17(1):53. doi: 10.1186/s12876-0170605-x

73. De Marco S, Sichetti M, Muradyan D, Piccioni M, Traina G, Pagiotti R, et al. Probiotic cell-free supernatants exhibited anti-inflammatory and antioxidant activity on human gut epithelial cells and macrophages stimulated with LPS. Evidence-Based Complement Altern Med (2018) 2018:1756308. doi: 10.1155/2018/1756308

74. Sichetti M, De Marco S, Pagiotti R, Traina G, Pietrella D. Anti-inflammatory effect of multistrain probiotic formulation (L. rhamnosus, B. lactis, and B. longum). Nutr Elsevier Inc (2018) 53:95-102. doi: 10.1016/j.nut.2018.02.005

75. Li SC, Hsu WF, Chang JS, Shih CK. Combination of lactobacillus acidophilus and bifidobacterium animalis subsp. Lactis shows a stronger anti-inflammatory effect than individual strains in HT-29 cells. Nutrients MDPI AG (2019) 11(5):969. doi: 10.3390/nu11050969

76. Sagheddu V, Uggeri F, Belogi L, Remollino L, Brun P, Bernabè G, et al. The Biotherapeutic Potential of Lactobacillus reuteri Characterized Using a 
Target-Specific Selection Process. Front Microbiol Front Media S A (2020) 11:532. doi: $10.3389 /$ fmicb.2020.00532

77. Aattouri N, Lemonnier D. Production of interferon induced by Streptococcus thermophilus: Role of CD4+ and CD8+ lymphocytes. J Nutr Biochem Elsevier (1997) 8(1):25-31. doi: 10.1016/S0955-2863(96) 00147-7

78. Haller D, Blum S, Bode C, Hammes WP, Schiffrin EJ. Activation of human peripheral blood mononuclear cells by nonpathogenic bacteria in vitro: Evidence of NK cells as primary targets. Infect Immun Am Soc Microbiol J (2000) 68(2):752-9. doi: 10.1128/IAI.68.2.752-759.2000

79. Cross ML, Stevenson LM, Gill HS. Anti-allergy properties of fermented foods: An important immunoregulatory mechanism of lactic acid bacteria? Int Immunopharmacol (2001) 1(5):891-901. doi: 10.1016/S1567-5769(01) 00025-X

80. Cross ML, Mortensen RR, Kudsk J, Gill HS. Dietary intake of Lactobacillus rhamnosus HN001 enhances production of both Th1 and Th2 cytokines in antigen-primed mice. Med Microbiol Immunol (2002) 191(1):49-53. doi: $10.1007 / \mathrm{s} 00430-002-0112-7$

81. Luerce TD, Gomes-Santos AC, Rocha CS, Moreira TG, Cruz DN, Lemos L, et al. Anti-inflammatory effects of Lactococcus lactis NCDO 2118 during the remission period of chemically induced colitis. Gut Pathog BioMed Cent Ltd (2014) 6(1):33. doi: 10.1186/1757-4749-6-33

82. Good M, Sodhi CP, Ozolek JA, Buck RH, Goehring KC, Thomas DL, et al. Lactobacillus rhamnosus HN001 decreases the severity of necrotizing enterocolitis in neonatal mice and preterm piglets: Evidence in mice for a role of TLR9. Am J Physiol Gastrointest Liver Physiol Am Physiol Soc (2014) 306(11):G1021-32. doi: 10.1152/ajpgi.00452.2013

83. Kwon HK, Lee CG, So JS, Chae CS, Hwang JS, Sahoo A, et al. Generation of regulatory dendritic cells and $\mathrm{CD} 4+\mathrm{Foxp} 3+\mathrm{T}$ cells by probiotics administration suppresses immune disorders. Proc Natl Acad Sci U.S.A. (2010) 107(5):2159-64. doi: 10.1073/pnas.0904055107

84. Mariman R, Kremer B, Koning F, Nagelkerken L. The probiotic mixture VSL3 mediates both pro- and anti-inflammatory responses in bone marrowderived dendritic cells from C57BL/6 and BALB/c mice. Br J Nutr Cambridge Univ Press (2014) 112(7):1088-97. doi: 10.1017/S000711451400169X

85. Kawano M, Miyoshi M, Miyazaki T. Lactobacillus helveticus SBT2171 induces A20 expression via toll-like receptor 2 signaling and inhibits the lipopolysaccharide-induced activation of nuclear factor-kappa B and mitogenactivated protein kinases in peritoneal macrophages. Front Immunol Front Media S A (2019) 112(7):1088-97. doi: 10.3389/fimmu.2019.00845

86. Lin YP, Thibodeaux CH, Peña JA, Ferry GD, Versalovic J. Probiotic Lactobacillus reuteri suppress proinflammatory cytokines via c-Jun. Inflammation Bowel Dis (2008) 14(8):1068-83. doi: 10.1002/ibd.20448

87. Griet M, Zelaya H, Mateos MV, Salva S, Juarez GE, De Valdez GF, et al. Soluble factors from Lactobacillus reuteri CRL1098 have anti-inflammatory effects in acute lung injury induced by lipopolysaccharide in mice. PloS One Public Library Sci (2014) 9(10):e110027. doi: 10.1371/journal.pone.0110027

88. Soria M, Mechoud M, Martin De Quevedo A, Font De Valdez G, Rodriguez AV. Disruption of lipid rafts enhances the effect of lactobacilli on the production of tumor necrosis factor-alpha in mononuclear blood cells. Biosci Biotechnol Biochem (2008) 72(12):3293-6. doi: 10.1271/bbb.80445

89. Thomas S, Metzke D, Schmitz J, Dörffel Y, Baumgart DC. Antiinflammatory effects of Saccharomyces boulardii mediated by myeloid dendritic cells from patients with Crohn's disease and ulcerative colitis. Am J Physiol Gastrointest Liver Physiol Am J Physiol Gastrointest Liver Physiol (2011) 301(6):G1083-92. doi: 10.1152/ajpgi.00217.2011

90. Thomas S, Przesdzing I, Metzke D, Schmitz J, Radbruch A, Baumgart DC. Saccharomyces boulardii inhibits lipopolysaccharide-induced activation of human dendritic cells and T cell proliferation. Clin Exp Immunol (2009) 156 (1):78-87. doi: 10.1111/j.1365-2249.2009.03878.x

91. Vinolo MAR, Rodrigues HG, Hatanaka E, Sato FT, Sampaio SC, Curi R. Suppressive effect of short-chain fatty acids on production of proinflammatory mediators by neutrophils. J Nutr Biochem (2011) 22 (9):849-55. doi: 10.1016/j.jnutbio.2010.07.009

92. Park JS, Lee EJ, Lee JC, Kim WK, Kim HS. Anti-inflammatory effects of short chain fatty acids in IFN- $\gamma$-stimulated RAW 264.7 murine macrophage cells: Involvement of NF- $\mathrm{KB}$ and ERK signaling pathways. Int Immunopharmacol (2007) 7(1):70-7. doi: 10.1016/j.intimp.2006.08.015
93. Kespohl M, Vachharajani N, Luu M, Harb H, Pautz S, Wolff S, et al. The microbial metabolite butyrate induces expression of Th1- associated factors in cD4+ T cells. Front Immunol (2017) 8:1036. doi: 10.3389/ fimmu.2017.01036

94. Sivieri K, Morales MLV, Adorno MAT, Sakamoto IK, Saad SMI, Rossi EA. Lactobacillus acidophilus CRL 1014 improved " gut health " in the SHIME $^{\circledR}$ reactor. BMC Gastroenterol (2013) 13(1):100. doi: 10.1186/ 1471-230X-13-100

95. LeBlanc JG, Chain F, Martín R, Bermúdez-Humarán LG, Courau S, Langella P. Beneficial effects on host energy metabolism of short-chain fatty acids and vitamins produced by commensal and probiotic bacteria. Microbial Cell (2017) 16(1):79. doi: 10.1186/s12934-017-0691-z

96. Venkatesh M, Mukherjee S, Wang H, Li H, Sun K, Benechet AP, et al. Symbiotic bacterial metabolites regulate gastrointestinal barrier function via the xenobiotic sensor PXR and toll-like receptor 4. Immunity Cell Press (2014) 41(2):296-310. doi: 10.1016/j.immuni.2014.06.014

97. Park JS, Choi JW, Jhun JY, Kwon JY, Lee BI, Yang CW, et al. Lactobacillus acidophilus Improves Intestinal Inflammation in an Acute Colitis Mouse Model by Regulation of Th17 and Treg Cell Balance and Fibrosis Development. J Med Food (2018) 21(3):215-24. doi: 10.1089/jmf.2017.3990

98. Zhou X, Liu H, Zhang J, Mu J, Zalan Z, Hegyi F, et al. Protective effect of Lactobacillus fermentum CQPC04 on dextran sulfate sodium-induced colitis in mice is associated with modulation of the nuclear factor- $\mathrm{\kappa B}$ signaling pathway. J Dairy Sci (2019) 102(11):9570-85. doi: 10.3168/ jds.2019-16840

99. Choi SH, Lee SH, Kim MG, Lee HJ, Kim GB. Lactobacillus plantarum CAU1055 ameliorates inflammation in lipopolysaccharide-induced RAW264.7 cells and a dextran sulfate sodium-induced colitis animal model. J Dairy Sci (2019) 102(8):6718-25. doi: 10.3168/jds.2018-16197

100. Chen L, Zou Y, Peng J, Lu F, Yin Y, Li F, et al. Lactobacillus acidophilus suppresses colitis-associated activation of the IL-23/Th17 axis. J Immunol Res Hindawi Publishing Corporation (2015) 2015:909514. doi: 10.1155/2015/ 909514

101. Gao C, Major A, Rendon D, Lugo M, Jackson V, Shi Z, et al. Histamine H2 receptor-mediated suppression of intestinal inflammation by probiotic lactobacillus reuteri. MBio. Am Soc Microbiol (2015) 6(6):e01358-15. doi: 10.1128/mBio.01358-15

102. Qiu X, Zhang M, Yang X, Hong N, Yu C. Faecalibacterium prausnitzii upregulates regulatory $\mathrm{T}$ cells and anti-inflammatory cytokines in treating TNBS-induced colitis. J Crohn's Colitis (2013) 7(11):e558-68. doi: 10.1016/ j.crohns.2013.04.002

103. Rodríguez-Nogales A, Algieri F, Garrido-Mesa J, Vezza T, Utrilla MP, Chueca $\mathrm{N}$, et al. Differential intestinal anti-inflammatory effects of Lactobacillus fermentum and Lactobacillus salivarius in DSS mouse colitis: impact on microRNAs expression and microbiota composition. Mol Nutr Food Res (2017) 61(11):10.1002/mnfr.201700144. doi: 10.1002/ mnfr.201700144

104. Kanda T, Nishida A, Ohno M, Imaeda H, Shimada T, Inatomi O, et al. Enterococcus durans TN-3 induces regulatory $\mathrm{T}$ cells and suppresses the development of dextran sulfate sodium (DSS)-induced experimental colitis. PloS One (2016) 11(7):e0159705. doi: 10.1371/journal.pone.0159705

105. Dogi C, García G, De Moreno de LeBlanc A, Greco C, Cavaglieri L. Lactobacillus rhamnosus RC007 intended for feed additive: Immunestimulatory properties and ameliorating effects on TNBS-induced colitis. Benef Microbes (2016) 7(4):539-47. doi: 10.3920/BM2015.0147

106. Huang L, Zhao Z, Duan C, Wang C, Zhao Y, Yang G, et al. Lactobacillus plantarum C88 protects against aflatoxin B1-induced liver injury in mice via inhibition of NF- $\mathrm{KB}$-mediated inflammatory responses and excessive apoptosis. BMC Microbiol (2019) 19(1):170. doi: 10.1186/s12866-0191525-4

107. Tang Y, Wu Y, Huang Z, Dong W, Deng Y, Wang F, et al. Administration of probiotic mixture DM1 ameliorated 5-fluorouracil-induced intestinal mucositis and dysbiosis in rats. Nutrition (2017) 33:96-104. doi: 10.1016/ j.nut.2016.05.003

108. Mi H, Dong Y, Zhang B, Wang H, Peter CCK, Gao P, et al. Bifidobacterium Infantis Ameliorates Chemotherapy-Induced Intestinal Mucositis Via Regulating T Cell Immunity in Colorectal Cancer Rats. Cell Physiol Biochem (2017) 42(6):2330-41. doi: 10.1159/000480005 
109. Cervantes-Barragan L, Chai JN, Tianero MD, Di Luccia B, Ahern PP, Merriman J, et al. Lactobacillus reuteri induces gut intraepithelial CD4 +CD8 $\alpha \alpha+$ T cells. Sci (80- ) (2017) 357(6353):806-10. doi: 10.1126/ science.aah5825

110. Husby S, Koletzko S, Korponay-Szabó I, Kurppa K, Mearin ML, RibesKoninckx C, et al. European Society Paediatric Gastroenterology, Hepatology and Nutrition Guidelines for Diagnosing Coeliac Disease 2020. J Pediatr Gastroenterol Nutr (2020) 70:141-56. doi: 10.1097/ MPG.0000000000002497

111. Cristofori F, Indrio F, Miniello VL, De Angelis M, Francavilla R. Probiotics in celiac disease. Nutrients (2018) 10(12):1824. doi: 10.3390/nu10121824.

112. Leonard MM, Camhi S, Huedo-Medina TB, Fasano A. Celiac disease genomic, environmental, microbiome, and metabolomic (CDGEMM) study design: Approach to the future of personalized prevention of celiac disease. Nutrients (2015) 7(11):9325-36. doi: 10.3390/nu7115470

113. Francavilla R, De Angelis M, Rizzello CG, Cavallo N, Dal Bello F, Gobbetti M. Selected probiotic lactobacilli have the capacity to hydrolyze gluten peptides during simulated gastrointestinal digestion. Appl Environ Microbiol Am Soc Microbiol (2017) 83(14):e00376-17. doi: 10.1128/ AEM.00376-17

114. Francavilla R, Cristofori F, Vacca M, Barone M, De Angelis M. Advances in understanding the potential therapeutic applications of gut microbiota and probiotic mediated therapies in celiac disease. Expert Rev Gastroenterol Hepatol (2020) 14:323-33. doi: 10.1080/17474124.2020.1745630

115. D'Arienzo R, Maurano F, Luongo D, Mazzarella G, Stefanile R, Troncone R, et al. Adjuvant effect of Lactobacillus casei in a mouse model of gluten sensitivity. Immunol Lett (2008) 119(1-2):78-83. doi: 10.1016/j.imlet.2008. 04.006

116. D'Arienzo R, Stefanile R, Maurano F, Mazzarella G, Ricca E, Troncone R, et al. Immunomodulatory effects of Lactobacillus casei administration in a mouse model of gliadin-sensitive enteropathy. Scand J Immunol (2011) 74 (4):335-41. doi: 10.1111/j.1365-3083.2011.02582.x

117. Papista C, Gerakopoulos V, Kourelis A, Sounidaki M, Kontana A, Berthelot $\mathrm{L}$, et al. Gluten induces coeliac-like disease in sensitised mice involving IgA, CD71 and transglutaminase 2 interactions that are prevented by probiotics. Lab Investig (2012) 92(4):625-35. doi: 10.1038/labinvest.2012.13

118. Lindfors K, Blomqvist T, Juuti-Uusitalo K, Stenman S, Venäläinen J, Mäki M, et al. Live probiotic Bifidobacterium lactis bacteria inhibit the toxic effects induced by wheat gliadin in epithelial cell culture. Clin Exp Immunol (2008) 152(3):552-8. doi: 10.1111/j.1365-2249.2008.03635.x

119. Laparra JM, Olivares M, Gallina O, Sanz Y. Bifidobacterium longum CECT 7347 modulates immune responses in a gliadin-induced enteropathy animal model. PloS One (2012) 7(2):e30744. doi: 10.1371/journal.pone.0030744

120. Håkansson Å, Aronsson CA, Brundin C, Oscarsson E, Molin G, Agardh D. Effects of lactobacillus plantarum and lactobacillus paracasei on the peripheral immune response in children with celiac disease autoimmunity: A randomized, double-blind, placebo-controlled clinical trial. Nutrients MDPI AG (2019) 11(8):1925. doi: 10.3390/nu11081925

121. Klemenak M, Dolinšek J, Langerholc T, Di Gioia D, Mičetić-Turk D. Administration of Bifidobacterium breve Decreases the Production of TNF- $\alpha$ in Children with Celiac Disease. Dig Dis Sci (2015) 60(11):338692. doi: 10.1007/s10620-015-3769-7

122. Primec M, Klemenak M, Di Gioia D, Aloisio I, Bozzi Cionci N, Quagliariello A, et al. Clinical intervention using Bifidobacterium strains in celiac disease children reveals novel microbial modulators of TNF- $\alpha$ and short-chain fatty acids. Clin Nutr (2019) 38(3):1373-81. doi: 10.1016/j.clnu.2018.06.931

123. Olivares M, Castillejo G, Varea V, Sanz Y. Double-blind, randomised, placebo-controlled intervention trial to evaluate the effects of Bifidobacterium longum CECT 7347 in children with newly diagnosed coeliac disease. Br J Nutr (2014) 112(1):30-40. doi: 10.1017/ S0007114514000609

124. Olivares M, Laparra M, Sanz Y. Oral administration of Bifidobacterium longum CECT 7347 modulates jejunal proteome in an in vivo gliadininduced enteropathy animal model. J Proteomics (2012) 77:310-20. doi: $10.1016 /$ j.jprot.2012.09.005

125. Francavilla R, Piccolo M, Francavilla A, Polimeno L, Semeraro F, Cristofori F, et al. Clinical and Microbiological Effect of a Multispecies Probiotic Supplementation in Celiac Patients with Persistent IBS-type Symptoms: A
Randomized, Double-Blind, Placebo-controlled, Multicenter Trial. J Clin Gastroenterol (2019) 53(3):E117-25. doi: 10.1097/MCG.0000000000001023

126. Giorgi A, Cerrone R, Capobianco D, Filardo S, Mancini P, Zanni F, et al. A probiotic preparation hydrolyzes gliadin and protects intestinal cells from the toxicity of pro-inflammatory peptides. Nutrients MDPI AG (2020) 12 (2):495. doi: 10.3390/nu12020495

127. Manichanh C, Borruel N, Casellas F, Guarner F. The gut microbiota in IBD. Nat Rev Gastroenterol Hepatol (2012) 9:599-608. doi: 10.1038/ nrgastro.2012.152

128. Khor B, Gardet A, Xavier RJ. Genetics and pathogenesis of inflammatory bowel disease. Nature (2011) 474:307-17. doi: 10.1038/nature10209

129. Lloyd-Price J, Arze C, Ananthakrishnan AN, Schirmer M, Avila-Pacheco J, Poon TW, et al. Multi-omics of the gut microbial ecosystem in inflammatory bowel diseases. Nature Nat Publishing Group (2019) 569(7758):655-62. doi: 10.1038/s41586-019-1237-9

130. Frank DN, St. Amand AL, Feldman RA, Boedeker EC, Harpaz N, Pace NR. Molecular-phylogenetic characterization of microbial community imbalances in human inflammatory bowel diseases. Proc Natl Acad Sci U.S.A. (2007) 104(34):13780-5. doi: 10.1073/pnas.0706625104

131. Sartor RB, Wu GD. Roles for Intestinal Bacteria, Viruses, and Fungi in Pathogenesis of Inflammatory Bowel Diseases and Therapeutic Approaches. Gastroenterol W B Saunders (2017) 152(2):327-339.e4. doi: 10.1053/ j.gastro.2016.10.012

132. Chassaing B, Darfeuillemichaud A. The commensal microbiota and enteropathogens in the pathogenesis of inflammatory bowel diseases. Gastroenterol W B Saunders (2011) 140(6):1720-28.e3. doi: 10.1053/ j.gastro.2011.01.054

133. Fiorucci S, Distrutti E, Mencarelli A, Barbanti M, Palazzini E, Morelli A. Inhibition of intestinal bacterial translocation with rifaximin modulates lamina propria monocytic cells reactivity and protects against inflammation in a rodent model of colitis. Digestion (2002) 66(4):246-56. doi: $10.1159 / 000068362$

134. Loftus EV. Clinical epidemiology of inflammatory bowel disease: Incidence, prevalence, and environmental influences. Gastroenterol W B Saunders (2004) 126(6):1504-17. doi: 10.1053/j.gastro.2004.01.063

135. Ungaro R, Mehandru S, Allen PB, Peyrin-Biroulet L, Colombel JF. Ulcerative colitis. Lancet Lancet Publishing Group (2017) 389:1756-70. doi: 10.1016/ S0140-6736(16)32126-2

136. Matthes H, Krummenerl T, Giensch M, Wolff C, Schulze J. Clinical trial: Probiotic treatment of acute distal ulcerative colitis with rectally administered Escherichia coli Nissle 1917 (EcN). BMC Complement Altern Med BMC Complement Altern Med (2010) 10:13. doi: 10.1186/ 1472-6882-10-13

137. Oliva S, Di Nardo G, Ferrari F, Mallardo S, Rossi P, Patrizi G, et al. Randomised clinical trial: The effectiveness of Lactobacillus reuteri ATCC 55730 rectal enema in children with active distal ulcerative colitis. Aliment Pharmacol Ther (2012) 35(3):327-34. doi: 10.1111/j.1365-2036.2011. 04939.x

138. Tamaki H, Nakase H, Inoue S, Kawanami C, Itani T, Ohana M, et al. Efficacy of probiotic treatment with Bifidobacterium longum 536 for induction of remission in active ulcerative colitis: A randomized, double-blinded, placebo-controlled multicenter trial. Dig Endosc Blackwell Publishing (2016) 28(1):67-74. doi: 10.1111/den.12553

139. Kaur L, Gordon M, Baines PA, Iheozor-Ejiofor Z, Sinopoulou V, Akobeng AK. Probiotics for induction of remission in ulcerative colitis. Cochrane Database Systematic Rev NLM (Medline) (2020) 3:CD005573. doi: 10.1002/ 14651858.CD005573.pub3

140. Zocco MA, Dal Verme LZ, Cremonini F, Piscaglia AC, Nista EC, Candelli M, et al. Efficacy of Lactobacillus GG in maintaining remission of ulcerative colitis. Aliment Pharmacol Ther (2006) 23(11):1567-74. doi: 10.1111/j.13652036.2006.02927.x

141. Henker J, Müller S, Laass MW, Schreiner A, Schulze J. Probiotic Escherichia coli Nissle $1917(\mathrm{EcN})$ for successful remission maintenance of ulcerative colitis in children and adolescents: An open-label pilot study. Z Gastroenterol (2008) 46(9):874-5. doi: 10.1055/s-2008-1027463

142. Scaldaferri F, Gerardi V, Mangiola F, Lopetuso LR, Pizzoferrato M, Petito V, et al. Role and mechanisms of action of Escherichia coli nissle 1917 in the maintenance of remission in ulcerative colitis patients: an update. World J 
Gastroenterol Baishideng Publishing Group Co Limited (2016) 22:5505-11. doi: 10.3748 /wjg.v22.i24.5505

143. Guslandi M. Saccharomyces boulardii plus rifaximin in mesalamineintolerant ulcerative colitis. J Clin Gastroenterol (2010) 44:385. doi: 10.1097/MCG.0b013e3181cb4233

144. Sood A, Midha V, Makharia GK, Ahuja V, Singal D, Goswami P, et al. The Probiotic Preparation, VSL3 Induces Remission in Patients With Mild-toModerately Active Ulcerative Colitis. Clin Gastroenterol Hepatol $W B$ Saunders (2009) 7(11):1202-9, 1209.e1. doi: 10.1016/j.cgh.2009.07.016

145. Tursi A, Brandimarte G, Papa A, Giglio A, Elisei W, Giorgetti GM, et al. Treatment of relapsing mild-to-moderate ulcerative colitis with the probiotic VSL3 as adjunctive to a standard pharmaceutical treatment: A double-blind, randomized, placebo-controlled study. Am J Gastroenterol (2010) 105 (10):2218-27. doi: 10.1038/ajg.2010.218

146. Souza ÉL, Elian SD, Paula LM, Garcia CC, Vieira AT, Teixeira MM, et al. Escherichia coli strain Nissle 1917 ameliorates experimental colitis by modulating intestinal permeability, the inflammatory response and clinical signs in a faecal transplantation model. J Med Microbiol (2016) 65(3):201-10. doi: $10.1099 / \mathrm{jmm} .0 .000222$

147. Kruis W, Frič P, Pokrotnieks J, Lukáš M, Fixa B, Kašćák M, et al. Maintaining remission of ulcerative colitis with the probiotic Escherichia coli Nissle 1917 is as effective as with standard mesalazine. Gut (2004) 53(11):1617-23. doi: 10.1136/gut.2003.037747

148. Iheozor-Ejiofor Z, Kaur L, Gordon M, Baines PA, Sinopoulou V, Akobeng AK. Probiotics for maintenance of remission in ulcerative colitis. Cochrane Database Systematic Rev NLM (Medline) (2020) 3:CD007443. doi: 10.1002/ 14651858.CD007443.pub3

149. Gionchetti P, Rizzello F, Helwig U, Venturi A, Lammers KM, Brigidi P, et al. Prophylaxis of pouchitis onset with probiotic therapy: A double-blind, placebo-controlled trial. Gastroenterol W B Saunders (2003) 124(5):1202 -9. doi: 10.1016/S0016-5085(03)00171-9

150. Gionchetti P, Rizzello F, Venturi A, Brigidi P, Matteuzzi D, Bazzocchi G, et al. Oral bacteriotherapy as maintenance treatment in patients with chronic pouchitis: A double-blind, placebo-controlled trial. Gastroenterology (2000) 119(2):305-9. doi: 10.1053/gast.2000.9370

151. Mimura T, Rizzello F, Helwig U, Poggioli G, Schreiber S, Talbot IC, et al. Once daily high dose probiotic therapy (VSL\#3) for maintaining remission in recurrent or refractory pouchitis. Gut (2004) 53(1):108-14. doi: 10.1136/ gut.53.1.108

152. Pronio A, Montesani C, Butteroni C, Vecchione S, Mumolo G, Vestri AR, et al. Probiotic administration in patients with ileal pouch-anal anastomosis for ulcerative colitis is associated with expansion of mucosal regulatory cells. Inflammation Bowel Dis (2008) 14(5):662-8. doi: 10.1002/ibd.20369

153. Landy J, Hart A. Invited Commentaries: Commentary: the effects of probiotics on barrier function and mucosal pouch microbiota during maintenance treatment for severe pouchitis in patients with ulcerative colitis. Alimentary Pharmacol Ther Aliment Pharmacol Ther (2013) 38:1405-6. doi: 10.1111/apt.12517

154. Manichanh C, Rigottier-Gois L, Bonnaud E, Gloux K, Pelletier E, Frangeul L, et al. Reduced diversity of faecal microbiota in Crohn's disease revealed by a metagenomic approach. Gut (2006) 55(2):205-11. doi: 10.1136/ gut.2005.073817

155. Willing BP, Dicksved J, Halfvarson J, Andersson AF, Lucio M, Zheng Z, et al. A pyrosequencing study in twins shows that gastrointestinal microbial profiles vary with inflammatory bowel disease phenotypes. Gastroenterol W B Saunders (2010) 139(6):1844-54.e1. doi: 10.1053/j.gastro.2010.08.049

156. Darfeuille-Michaud A, Boudeau J, Bulois P, Neut C, Glasser AL, Barnich N, et al. High prevalence of adherent-invasive Escherichia coli associated with ileal mucosa in Crohn's disease. Gastroenterol W B Saunders (2004) 127 (2):412-21. doi: 10.1053/j.gastro.2004.04.061

157. Lapaquette P, Glasser AL, Huett A, Xavier RJ, Darfeuille-Michaud A. Crohn's disease-associated adherent-invasive E. coli are selectively favoured by impaired autophagy to replicate intracellularly. Cell Microbiol (2010) 12(1):99-113. doi: 10.1111/j.1462-5822.2009.01381.x

158. Derwa Y, Gracie DJ, Hamlin PJ, Ford AC. Systematic review with metaanalysis: the efficacy of probiotics in inflammatory bowel disease. Alimentary Pharmacol Ther Blackwell Publishing Ltd (2017) 46:389-400. doi: 10.1111/ apt. 14203
159. Rolfe VE, Fortun PJ, Hawkey CJ, Bath-Hextall F. Probiotics for maintenance of remission in Crohn's disease. Cochrane Database Systematic Rev John Wiley Sons Ltd (2006). doi: 10.1002/14651858.CD004826.pub2

160. Lacy BE, Mearin F, Chang L, Chey WD, Lembo AJ, Simren M, et al. Bowel disorders. Gastroenterol W B Saunders (2016) 150(6):1393-1407.e5. doi: 10.1053/j.gastro.2016.02.031

161. Hyams JS, Di Lorenzo C, Saps M, Shulman RJ, Staiano A, Van Tilburg M. Childhood functional gastrointestinal disorders: Child/adolescent. Gastroenterol W B Saunders (2016) 150(6):1456-1468.e2. doi: 10.1053/ j.gastro.2016.02.015

162. Rea K, O'Mahony SM, Dinan TG, Cryan JF. The role of the gastrointestinal microbiota in visceral pain. Handb Exp Pharmacol Springer New Y LLC (2017) 239:269-87. doi: 10.1007/164_2016_115

163. Simrén M, Öhman L. Pathogenesis of IBS: Role of inflammation, immunity and neuroimmune interactions. Nat Rev Gastroenterol Hepatol Nat Rev Gastroenterol Hepatol (2010) 7:163-73. doi: 10.1038/nrgastro.2010.4

164. Tap J, Derrien M, Törnblom H, Brazeilles R, Cools-Portier S, Doré J, et al. Identification of an Intestinal Microbiota Signature Associated With Severity of Irritable Bowel Syndrome. Gastroenterol W B Saunders (2017) 152 (1):111-123.e8. doi: 10.1053/j.gastro.2016.09.049

165. Liu HN, Wu H, Chen YZ, Chen YJ, Shen XZ, Liu TT. Altered molecular signature of intestinal microbiota in irritable bowel syndrome patients compared with healthy controls: A systematic review and meta-analysis. Digest Liver Dis Elsevier B V (2017) 49:331-7. doi: 10.1016/j.dld.2017.01.142

166. Pittayanon R, Lau JT, Yuan Y, Leontiadis GI, Tse F, Surette M, et al. Gut Microbiota in Patients With Irritable Bowel Syndrome-A Systematic Review. Gastroenterol W B Saunders (2019) 157(1):97-108. doi: 10.1053/ j.gastro.2019.03.049

167. Sundin J, Rangel I, Kumawat AK, Hultgren-Hörnquist E, Brummer RJ. Aberrant mucosal lymphocyte number and subsets in the colon of postinfectious irritable bowel syndrome patients. Scand J Gastroenterol Informa Healthcare (2014) 49(9):1068-75. doi: 10.3109/00365521.2014.926982

168. Downs IA, Aroniadis OC, Kelly L, Brandt LJ. Postinfection Irritable Bowel Syndrome: The Links between Gastroenteritis, Inflammation, the Microbiome, and Functional Disease. J Clin Gastroenterol Lippincott Williams Wilkins (2017) 51:869-77. doi: 10.1097/MCG.0000000000000924

169. Kim J, Cho K, Kim JS, Jung HC, Kim B, Park MS, et al. Probiotic treatment induced change of inflammation related metabolites in IBS-D patients/ double-blind, randomized, placebo-controlled trial. Food Sci Biotechnol Korean Soc Food Sci Technol (2020) 29(6):837-44. doi: 10.1007/s10068019-00717-2

170. O’Mahony L, Mccarthy J, Kelly P, Hurley G, Luo F, Chen K, et al. Lactobacillus and Bifidobacterium in irritable bowel syndrome: Symptom responses and relationship to cytokine profiles. Gastroenterol W B Saunders (2005) 128(3):541-51. doi: 10.1053/j.gastro.2004.11.050

171. Hod K, Sperber AD, Ron Y, Boaz M, Dickman R, Berliner S, et al. A doubleblind, placebo-controlled study to assess the effect of a probiotic mixture on symptoms and inflammatory markers in women with diarrhea-predominant IBS. Neurogastroenterol Motil Blackwell Publishing Ltd (2017) 29(7):10.1111/ nmo.13037. doi: 10.1111/nmo.13037

172. Zhang Y, Li L, Guo C, Mu D, Feng B, Zuo X, et al. Effects of probiotic type, dose and treatment duration on irritable bowel syndrome diagnosed by Rome III criteria: A meta-analysis. BMC Gastroenterol BioMed Cent Ltd (2016) 16(1):62. doi: 10.1186/s12876-016-0470-z

173. Ford AC, Quigley EMM, Lacy BE, Lembo AJ, Saito YA, Schiller LR, et al. Efficacy of prebiotics, probiotics, and synbiotics in irritable bowel syndrome and chronic idiopathic constipation: systematic review and meta-analysis. Am J Gastroenterol (2014) 109(10):1547-62. doi: 10.1038/ajg.2014.202

174. Zhao Q, Yang WR, Wang XH, Li GQ, Xu LQ, Cui X, et al. Clostridium butyricum alleviates intestinal low-grade inflamm TNBS-induced irritable bowel syndrome in mice by regulating functional status of lamina propria dendritic cells. World J Gastroenterol Baishideng Publishing Group Co Limited (2019) 25(36):5469-82. doi: 10.3748/wjg.v25.i36.5469

175. Wang H, Gong J, Wang W, Long Y, Fu X, Fu Y, et al. Are there any different effects of Bifidobacterium, Lactobacillus and Streptococcus on intestinal sensation, barrier function and intestinal immunity in PI-IBS mouse model? PloS One Public Library Sci (2014) 9(3):e90153. doi: 10.1371/ journal.pone.0090153 
176. Abbas Z, Yakoob J, Jafri W, Ahmad Z, Azam Z, Usman MW, et al. Cytokine and clinical response to Saccharomyces boulardii therapy in diarrheadominant irritable bowel syndrome: A randomized trial. Eur $J$ Gastroenterol Hepatol Lippincott Williams Wilkins (2014) 26(6):630-9. doi: 10.1097/MEG.0000000000000094

177. Guarino A, Canani RB. Probiotics in Childhood Diseases: From Basic Science to Guidelines in 20 Years of Research and Development. J Pediatr Gastroenterol Nutr (2016) 63:S1-2. doi: 10.1097/MPG.0000000000001220

178. Bray GA, Kim KK, Wilding JPH. Obesity: a chronic relapsing progressive disease process. A position statement of the World Obesity Federation. Obes Rev Blackwell Publishing Ltd (2017) 18(7):715-23. doi: 10.1111/obr.12551

179. Rastelli M, Knauf C, Cani PD. Gut Microbes and Health: A Focus on the Mechanisms Linking Microbes, Obesity, and Related Disorders. Obes Blackwell Publishing Inc (2018) 26:792-800. doi: 10.1002/oby.22175

180. Jumpertz R, Le DS, Turnbaugh PJ, Trinidad C, Bogardus C, Gordon JI, et al. Energy-balance studies reveal associations between gut microbes, caloric load, and nutrient absorption in humans. Am J Clin Nutr (2011) 94(1):58-65. doi: 10.3945/ajcn.110.010132

181. Angelakis E, Armougom F, Million M, Raoult D. The relationship between gut microbiota and weight gain in humans. Future Microbiol (2012) 7:91-109. doi: $10.2217 /$ fmb.11.142

182. Duncan SH, Lobley GE, Holtrop G, Ince J, Johnstone AM, Louis P, et al. Human colonic microbiota associated with diet, obesity and weight loss. Int $J$ Obes (2008) 32(11):1720-4. doi: 10.1038/ijo.2008.155

183. Vallianou N, Stratigou T, Christodoulatos GS, Dalamaga M. Understanding the Role of the Gut Microbiome and Microbial Metabolites in Obesity and Obesity-Associated Metabolic Disorders: Current Evidence and Perspectives. Curr Obes Rep (2019) 8(3):317-32. doi: 10.1007/s13679-019-00352-2

184. Kalliomäki M, Collado MC, Salminen S, Isolauri E. Early differences in fecal microbiota composition in children may predict overweight. Am J Clin Nutr (2008) 87(3):534-8. doi: 10.1093/ajcn/87.3.534

185. Cox AJ, West NP, Cripps AW. Obesity, inflammation, and the gut microbiota. Lancet Diabetes Endocrinol (2015) 3:207-15. doi: 10.1016/ S2213-8587(14)70134-2

186. Torres-Fuentes C, Schellekens H, Dinan TG, Cryan JF. The microbiota-gutbrain axis in obesity. Lancet Gastroenterol Hepatol (2017) 2:747-56. doi: 10.1016/S2468-1253(17)30147-4

187. Naito E, Yoshida Y, Makino K, Kounoshi Y, Kunihiro S, Takahashi R, et al. Beneficial effect of oral administration of Lactobacillus casei strain Shirota on insulin resistance in diet-induced obesity mice. J Appl Microbiol (2011) 110 (3):650-7. doi: 10.1111/j.1365-2672.2010.04922.x

188. Ferrarese R, Ceresola ER, Preti A, Canducci F. Probiotics, prebiotics and synbiotics for weight loss and metabolic syndrome in the microbiome era. Eur Rev Med Pharmacol Sci (2018) 22(21):7588-605. doi: 10.26355/eurrev201811-16301

189. Ejtahed HS, Angoorani P, Soroush AR, Atlasi R, Hasani-Ranjbar S, Mortazavian AM, et al. Probiotics supplementation for the obesity management; A systematic review of animal studies and clinical trials. J Funct Foods Elsevier Ltd (2019) 52:228-42. doi: 10.1016/j.jff.2018.10.039

190. Ben Salah R, Trabelsi I, Hamden K, Chouayekh H, Bejar S. Lactobacillus plantarum TN8 exhibits protective effects on lipid, hepatic and renal profiles in obese rat. Anaerobe (2013) 23:55-61. doi: 10.1016/j.anaerobe.2013.07.003

191. Miyoshi M, Ogawa A, Higurashi S, Kadooka Y. Anti-obesity effect of Lactobacillus gasseri SBT2055 accompanied by inhibition of proinflammatory gene expression in the visceral adipose tissue in dietinduced obese mice. Eur J Nutr (2014) 53(2):599-606. doi: 10.1007/ s00394-013-0568-9

192. Park DY, Ahn YT, Park SH, Huh CS, Yoo SR, Yu R, et al. Supplementation of Lactobacillus curvatus KY1032 in Diet-Induced Obese Mice Is Associated with Gut Microbial Changes and Reduction in Obesity. PloS One (2013) 8(3): e59470. doi: 10.1371/journal.pone.0059470

193. Everard A, Matamoros S, Geurts L, Delzenne NM, Cani PD. Saccharomyces boulardii administration changes gut microbiota and reduces hepatic steatosis, low-grade inflammation, and fat mass in obese and type 2 diabetic db/db mice. MBio Am Soc Microbiol (2014) 5(3):e01011-14. doi: 10.1128/mBio.01011-14

194. Bernini LJ, Simão ANC, Alfieri DF, Lozovoy MAB, Mari NL, de Souza CHB, et al. Beneficial effects of Bifidobacterium lactis on lipid profile and cytokines in patients with metabolic syndrome: A randomized trial. Effects Probiot Metab Syndrome (2016) 32(6):716-9. doi: 10.1016/j.nut.2015.11.001

195. Tenorio-Jiménez C, Martínez-Ramírez MJ, Del Castillo-Codes I, ArraizaIrigoyen C, Tercero-Lozano M, Camacho J, et al. Lactobacillus reuteri v3401 reduces inflammatory biomarkers and modifies the gastrointestinal microbiome in adults with metabolic syndrome: The PROSIR study. Nutrients (2019) 11(8):1761. doi: 10.3390/nu11081761

196. Koutnikova H, Genser B, Monteiro-Sepulveda M, Faurie JM, Rizkalla S, Schrezenmeir J, et al. Impact of bacterial probiotics on obesity, diabetes and non-alcoholic fatty liver disease related variables: A systematic review and meta-analysis of randomised controlled trials. BMJ Open (2019) 9(3): e017995. doi: 10.1136/bmjopen-2017-017995

197. Borgeraas H, Johnson LK, Skattebu J, Hertel JK, Hjelmesæth J. Effects of probiotics on body weight, body mass index, fat mass and fat percentage in subjects with overweight or obesity: a systematic review and meta-analysis of randomized controlled trials. Obes Rev Blackwell Publishing Ltd (2018) 19:219-32. doi: 10.1111/obr.12626

198. Czajeczny D, Kabzińska K, Wójciak RW. Does probiotic supplementation aid weight loss? A randomized, single-blind, placebo-controlled study with Bifidobacterium lactis BS01 and Lactobacillus acidophilus LA02 supplementation. Eat Weight Disord (2020) 10.1007/s40519-020-00983-8:1-9. doi: 10.1007/s40519-020-00983-8

199. Battle DE. Diagnostic and Statistical Manual of Mental Disorders (DSM). CoDAS Am Psychiatr Assoc (2013) 25(2):191-2. doi: 10.1590/s231717822013000200017

200. Sherwin E, Sandhu KV, Dinan TG, Cryan JF. May the Force Be With You: The Light and Dark Sides of the Microbiota-Gut-Brain Axis in Neuropsychiatry. CNS Drugs (2016) 30(11):1019-41. doi: 10.1007/s40263016-0370-3

201. Parracho HMRT, Bingham MO, Gibson GR, McCartney AL. Differences between the gut microflora of children with autistic spectrum disorders and that of healthy children. J Med Microbiol (2005) 54(10):987-91. doi: 10.1099/ jmm.0.46101-0

202. Finegold SM. Desulfovibrio species are potentially important in regressive autism. Med Hypotheses (2011) 77(2):270-4. doi: 10.1016/j.mehy.2011. 04.032

203. Tomova A, Husarova V, Lakatosova S, Bakos J, Vlkova B, Babinska K, et al. Gastrointestinal microbiota in children with autism in Slovakia. Physiol Behav (2015) 138:179-87. doi: 10.1016/j.physbeh.2014.10.033

204. Theoharides TC, Angelidou A, Alysandratos KD, Zhang B, Asadi S, Francis K, et al. Mast cell activation and autism. Biochim Biophys Acta Mol Basis Dis Biochim Biophys Acta (2012) 1822:34-41. doi: 10.1016/ j.bbadis.2010.12.017

205. Saghazadeh A, Ataeinia B, Keynejad K, Abdolalizadeh A, HirbodMobarakeh A, Rezaei N. A meta-analysis of pro-inflammatory cytokines in autism spectrum disorders: Effects of age, gender, and latitude. J Psychiatr (2019) 115:90-102. doi: 10.1016/j.jpsychires.2019.05.019

206. de Theije CGM, Wopereis H, Ramadan M, van Eijndthoven T, Lambert J, Knol J, et al. Altered gut microbiota and activity in a murine model of autism spectrum disorders. Brain Behav Immun (2014) 37:197-206. doi: 10.1016/ j.bbi.2013.12.005

207. Sanikhani NS, Modarressi MH, Jafari P, Vousooghi N, Shafei S, Akbariqomi $\mathrm{M}$, et al. The Effect of Lactobacillus casei Consumption in Improvement of Obsessive-Compulsive Disorder: an Animal Study. Probiot Antimicrob Proteins (2020) 12(4):1409-19. doi: 10.1007/s12602-020-09642-x

208. Parracho HMRT, Gibson GR, Knott F, Bosscher D, Kleerebezem M, McCartney AL. A double-blind, placebo-controlled, crossover-designed probiotic feeding study in children diagnosed with autistic spectrum disorders. Int J Probiot Prebiot (2010) 5(2):69-74.

209. De Angelis M, Piccolo M, Vannini L, Siragusa S, De Giacomo A, Serrazzanetti DI, et al. Fecal Microbiota and Metabolome of Children with Autism and Pervasive Developmental Disorder Not Otherwise Specified. PloS One (2013) 8(10):e76993. doi: 10.1371/journal.pone.0076993

210. De Angelis M, Francavilla R, Piccolo M, De Giacomo A, Gobbetti M. Autism spectrum disorders and intestinal microbiota. Gut Microbes (2015) 6(3):207 -13. doi: 10.1080/19490976.2015.1035855

211. Tysnes OB, Storstein A. Epidemiology of Parkinson's disease. J Neural Transm (2017) 124:901-5. doi: 10.1007/s00702-017-1686-y 
212. Forsyth CB, Shannon KM, Kordower JH, Voigt RM, Shaikh M, Jaglin JA, et al. Increased intestinal permeability correlates with sigmoid mucosa alpha-synuclein staining and endotoxin exposure markers in early Parkinson's disease. PloS One (2011) 6(12):e28032. doi: 10.1371/journal. pone. 0028032

213. Houser MC, Chang J, Factor SA, Molho ES, Zabetian CP, Hill-Burns EM, et al. Stool Immune Profiles Evince Gastrointestinal Inflammation in Parkinson's Disease. Mov Disord (2018) 33(5):793-804. doi: 10.1002/mds.27326

214. Wallen ZD, Appah M, Dean MN, Sesler CL, Factor SA, Molho E, et al. Characterizing dysbiosis of gut microbiome in PD: evidence for overabundance of opportunistic pathogens. NPJ Park Dis (2020) 6(1):11. doi: 10.1038/s41531-020-0112-6

215. Magistrelli L, Amoruso A, Mogna L, Graziano T, Cantello R, Pane M, et al. Probiotics may have beneficial effects in Parkinson's disease: In vitro evidence. Front Immunol (2019) 10:969:969. doi: 10.3389/fimmu.2019.00969

216. Srivastav S, Neupane S, Bhurtel S, Katila N, Maharjan S, Choi H, et al. Probiotics mixture increases butyrate, and subsequently rescues the nigral dopaminergic neurons from MPTP and rotenone-induced neurotoxicity. J Nutr Biochem (2019) 69:73-86. doi: 10.1016/j.jnutbio.2019.03.021
217. Tamtaji OR, Taghizadeh M, Daneshvar Kakhaki R, Kouchaki E, Bahmani F, Borzabadi S, et al. Clinical and metabolic response to probiotic administration in people with Parkinson's disease: A randomized, double-blind, placebocontrolled trial. Clin Nutr (2019) 38(3):1031-5. doi: 10.1016/j.clnu.2018.05.018

Conflict of Interest: RF is the inventor of the patent N 0001425900, released on 17 November 2016 (Italy).

The remaining authors declare that the research was conducted in the absence of any commercial or financial relationships that could be construed as a potential conflict of interest.

Copyright $\odot 2021$ Cristofori, Dargenio, Dargenio, Miniello, Barone and Francavilla. This is an open-access article distributed under the terms of the Creative Commons Attribution License (CC BY). The use, distribution or reproduction in other forums is permitted, provided the original author $(s)$ and the copyright owner(s) are credited and that the original publication in this journal is cited, in accordance with accepted academic practice. No use, distribution or reproduction is permitted which does not comply with these terms. 